Saeed Eini, Hamid Reza Shahhosseini, Majid Javidi, Mahdi Sharifzadeh, Davood Rashtchian. Inherently safe and economically optimal design using multi-objective optimization: The case of a refrigeration cycle. Process Safety and Environmental Protection, 2016, 104 (Part A), 254-267.

\title{
Inherently safe and economically optimal design using multi-objective optimization: the case of a refrigeration cycle
}

Saeed Eini ${ }^{\mathrm{a}}$, Hamid Reza Shahhosseini ${ }^{\mathrm{a}}$, Majid Javidi ${ }^{\mathrm{b}}$, Mahdi Sharifzadeh ${ }^{\mathrm{c}, *}$, Davood Rashtchian $^{\mathrm{a}}$

${ }^{a}$ Center for Process Design, Safety and Loss Prevention (CPSL), Chemical and Petroleum Engineering Department, Sharif University of Technology, Tehran, Iran

${ }^{\mathrm{b}}$ Iranian Offshore Engineering and Construction Company (IOEC)

${ }^{\mathrm{c}}$ Centre for Process System Engineering (CPSE), Department of Chemical Engineering, Imperial College London, United Kingdom

* Corresponding Author: Dr Mahdi Sharifzadeh; Room C603, Roderic Hill Building, South Kensington Campus, Imperial College London, UK. SW7 2AZ; Tel: +44(0)7517853422. E-mail address: mahdi@imperial.ac.uk 
Saeed Eini, Hamid Reza Shahhosseini, Majid Javidi, Mahdi Sharifzadeh, Davood Rashtchian. Inherently safe and economically optimal design using multi-objective optimization: The case of a refrigeration cycle. Process Safety and Environmental Protection, 2016, 104 (Part A), 254-267.

\section{Abstract}

2 The Economic viability of industrial processes strongly depends on their safe and reliable

3 operation. The method of inherent safe process design enables systematic consideration of safety

4 measures in order to ensure process safe operation at the early stages of process design. The

5 challenge is that the economic measures that are often considered for the design of industrial

6 processes are often incommensurable with the safety measures. In the present research, a novel

7 framework is proposed in which the safety criteria are quantified based on consequence

8 modeling and aggregated with the economic performance using multi-objective optimization

9 programming. The developed methodology was applied to the design of a simple refrigeration

10 cycle. The optimization algorithm was NSGA-II. The results suggested a strong trade-off

11 between the competing economic and safety objectives in terms of Pareto frontiers that clearly

12 quantified the required compromise. It was observed that only with a minor increase in the

13 capital investment, it is possible to significantly improve the safety. While the case of the LNG

14 refrigeration cycle was selected as a demonstrating case, the research methodology is to large

15 extend general and deemed to be acceptable to design and operation of other industrial processes.

16

\section{Keywords}

18 Inherent safety, Consequence Modeling, Multi-objective Optimization, Layout Optimization,

19 Simple refrigeration cycle

21 1. Introduction

22 The modern approach to chemical process safety is to apply risk management systems theory.

23 This includes identification of the hazards, and assess the associated risks, in order to reduce 
Saeed Eini, Hamid Reza Shahhosseini, Majid Javidi, Mahdi Sharifzadeh, Davood Rashtchian. Inherently safe and economically optimal design using multi-objective optimization: The case of a refrigeration cycle. Process Safety and Environmental Protection, 2016, 104 (Part A), 254-267.

24 them to an "as low as reasonably practicable" (ALARP) level, while balancing other business 25 objectives (CCPS, 2009). In general, the risk reduction policy, whether directed toward reducing

26 the occurrence or the severity of potential accidents, falls into one of the inherent, passive, 27 active, and procedural categories. The ideal way of dealing with a hazard is to remove it 28 completely if possible. This principle has been incorporated in the systematic application of 29 inherent safety (Mannan, 2013). The provision of the means to control the risk associated with a 30 hazard is very much the second best solution.

31 There are four basic principles to design an inherently safer process (Kletz, 1991): (1) Minimize:

32 use smaller quantities of hazardous substances (also called intensification); (2) Substitute: 33 replace a material with a less hazardous substance; (3) Moderate: use less hazardous conditions, 34 a less hazardous form of a material, or facilities that minimize the impact of a release of 35 hazardous material or energy (also called attenuation or limitation); (4) Simplify: design facilities 36 which eliminate unnecessary complexity and make operating errors less likely.

37 An inherently safer design (ISD) can either reduce the magnitude of a potential incident, or make 38 the occurrence of the accident highly unlikely, or perhaps impossible. Consequently, a process 39 that is inherently safer will require fewer and less robust, layers of protection (Mannan, 2013).

40 Although this strategic ideally should be implemented at an early stage in the process design 41 phase (CCPS, 2009), it may become necessary to implement the concepts of inherent safe design 42 and required major enhancements for existing plants at various phases of the process life cycle 43 (Khan and Amyotte, 2002, 2003; Mannan, 2013). As the process moves through its life cycle and 44 enters the operational phases, it becomes more difficult to change the basic process (CCPS, 45 2009). At the conceptual design stage, the process configuration and equipment design are 46 developed, their implications are explored, and potential problems are identified. In most cases, 
Saeed Eini, Hamid Reza Shahhosseini, Majid Javidi, Mahdi Sharifzadeh, Davood Rashtchian. Inherently safe and economically optimal design using multi-objective optimization: The case of a refrigeration cycle. Process Safety and Environmental Protection, 2016, 104 (Part A), 254-267.

47 the conceptual design stage may be quite short and associated with many uncertainties in the 48 involved physical and chemical phenomena and the process model parameters. However, if the

49 safety measures are neglected during the process design phase, it may have costly implications

50 during operational phases in terms of hazardous accidents and production interruptions.

51 Therefore, at the earliest phases of process design, the designers are encouraged to incorporate

52 ISD concepts. In order to do so, one can integrate these design concepts into the process design

53 by using optimization-based techniques (Mannan, 2013).

54 The inherent safety level can be evaluated either using (1) consequence modeling (calculation of

55 accidents' consequences) or (2) scoring the process features in terms of safety indices. The

56 majority of the research in the field has focused on developing safety indices in order to evaluate

57 the inherent safety level, for which extensive literature reviews are provided by Khan and 58 Amyotte (2003, 2005), Kletz and Amyotte (2010), and Khan et al. (2015). However, there are

59 little studies on the application of consequence modeling for designing inherently safer

60 processes. In the following, firstly, a brief survey of the methods which apply safety indices is

61 presented. Then the discussion continues with further elaboration of the methods which apply

62 consequence modeling for designing inherently safer processes. The aim is to identify the

63 research gaps and put the present research in the context.

64 The inherent safer design of heat exchanger network (HEN) has been the focus of researchers.

65 Chan et al. (2014) and Hafizan et al. (2016) integrated the STEP (stream temperature vs. 66 enthalpy plot) graphical approach and the inherent safety index (ISI) which had been developed

67 by Heikkilä (1999). In addition to the inherent safety concepts, Hafizan et al. (2016) considers 68 process operability of the HENs as well. 
Saeed Eini, Hamid Reza Shahhosseini, Majid Javidi, Mahdi Sharifzadeh, Davood Rashtchian. Inherently safe and economically optimal design using multi-objective optimization: The case of a refrigeration cycle. Process Safety and Environmental Protection, 2016, 104 (Part A), 254-267.

$69 \mathrm{Ng}$ et al. (2014a) proposed a framework in which various index-based methods can be selected

70 based on the availability of process data during process development and design. One of the

71 shortcomings of the index-based methods is scaling in which the physical or chemical properties

72 are divided into various ranges, in which each range has a score. The scaling procedure may

73 result in subjective measures and discontinuities at the sub-range boundaries. Ahmad et al.

74 (2014) proposed a new measure called Logistic function. Logistic function is a continuous

75 function that relates a score (as the dependent variable) to a safety parameter (as the independent

76 variable) in order to prevent discontinuity issues.

77 Ahmad et al. (2015) proposed a methodology in which the inherent safety of a separation process

78 is assessed during the design stage. In this approach, four parameters (volatility, toxicity,

79 flammability, and explosiveness) were used to find the total score in order to rank the alternative

80 designs. A systematic framework was proposed by $\mathrm{Ng}$ and Hassim (2015) to assist process

81 designers and engineers in assessing and reducing inherent occupational health hazards or

82 the potential risks based on process information availability. Pandian et al. (2015) proposed a

83 systematic methodology for designing an inherently healthier process during the R\&D stage

84 using ISD principles.

85 Groos-Gerardin et al. (2015) presented a framework by combining product engineering and

86 inherent safety to improve the powder impregnation process. They have used minimum ignition

87 energy as a measure of inherent safety. A combined approach for inherent safety and

88 environmental (CAISEN) assessment was presented by Ee et al. (2015). They integrated a life

89 cycle assessment (LCA) and the Inherent Safety Index (ISI) scoring system.

90 Several researchers have focused on developing inherently safer and healthier bioprocesses using

91 index-based approaches. $\mathrm{Ng}$ et al. (2013, 2014b) and Liew et al. (2014, 2015) utilized fuzzy 
Saeed Eini, Hamid Reza Shahhosseini, Majid Javidi, Mahdi Sharifzadeh, Davood Rashtchian. Inherently safe and economically optimal design using multi-objective optimization: The case of a refrigeration cycle. Process Safety and Environmental Protection, 2016, 104 (Part A), 254-267.

92 optimization approach in order to analyze inherent safety, health, environment, and economic

93 performance of biorefinaries. With respect to the same objectives, Liew et al. (2016) proposed a

94 sustainability assessment framework for a biorefinery including uncertainty in some parameters

95 (feed flow rate and price).

96 Ramadhan et al. (2014) developed a multi-objective fuzzy-based optimization model in order to

97 minimize work-related casualties within a palm-based bioprocess during its life cycle, while

98 simultaneously minimizing the operating costs. Due to the stochastic nature of workplace

99 accidents, realistic statistical data has been used for estimating the best possible pathway for the

100 desired process. $\mathrm{Ng}$ et al. (2015) presented a process-graph (P-graph) methodology for the

101 planning of bioenergy supply chains. The methodology was developed in order to take into

102 account both total cost minimization and supply chain risk reduction. The p-graph approach

103 enables embedded algorithms for solution structure generation and optimization to be used for

104 planning the supply chain. Ling et al. (2015) reviewed the sustainability assessment

105 methodologies which were used during the process synthesis of an integrated biorefinery system.

106 Ahmad et al. (2016) discussed the inherent safety assessment of biodiesel production pathways

107 from the flammability parameter. The numerical descriptive inherent safety technique (NuDIST)

108 for flammability score calculation was used in this research. Scarponi et al. (2016) proposed a

109 methodology for the selection of inherently safer biogas technology during early design stages.

110 In this method, Monte Carlo sensitivity analysis was applied for the uncertainty of the input

111 parameters and addressing the robustness of the ranked solutions.

112 The application of inherent safety indices is a simple approach to quantify the level of safety that

113 a process features. However, these methods only provide a relative evaluation of the level of risk

114 between different design options and do not consider vulnerable elements in the surrounding 
Saeed Eini, Hamid Reza Shahhosseini, Majid Javidi, Mahdi Sharifzadeh, Davood Rashtchian. Inherently safe and economically optimal design using multi-objective optimization: The case of a refrigeration cycle. Process Safety and Environmental Protection, 2016, 104 (Part A), 254-267.

115 environment that are the true hazard receptors. More importantly, these indices do not 116 demonstrate the potential economic benefits of implementing inherent safety strategies.

117 Quantification of the opportunities for ISD based on consequence modeling approach provides a 118 clearer understanding of the risk (Eini et al., 2015).

119 Several researchers have focused on developing computing tools based on consequence 120 modeling. Mohd Shariff et al. (2006) developed a tool called integrated risk estimation tool 121 (iRET) that applies the TNT equivalence method and the TNO correlation method to study 122 explosion consequences. Later, Shariff and Zaini (2010) developed toxic release consequence 123 analysis tool (TORCAT) in order to analyze the consequence of a toxic release. A model known 124 as inherent fire consequence estimation tool (IFCET) was developed by Shariff et al. (2016) to 125 assess process plant for the potential boiling liquid expanding vapor explosion (BLEVE).

126 Patel et al. (2010) integrated consequence modeling and regulatory guidance from 127 “environmental protection agency risk management program” (EPA RMP) in order to select 128 inherently safer solvents.

129 Jha et al., 2016 developed a hybrid methodology using both index-based and consequence 130 modeling-based methods in order to select the inherently safer design. In this framework, the 131 best process route and the inherent safety level of all process streams are estimated using 132 different indices. Finally, a risk assessment approach (based on consequence modeling) is 133 applied to the worst stream in order to evaluate the acceptability of the design. Methyl 134 methacrylate (MMA) routes were selected for demonstrating the methodology.

135 Unlike the abovementioned works which have not considered the plant economic during 136 incorporation of ISD concepts, Medina et al. (2009) have proposed an optimization methodology 137 in which both cost and risk were taken into account. They studied the optimum number of 
Saeed Eini, Hamid Reza Shahhosseini, Majid Javidi, Mahdi Sharifzadeh, Davood Rashtchian. Inherently safe and economically optimal design using multi-objective optimization: The case of a refrigeration cycle. Process Safety and Environmental Protection, 2016, 104 (Part A), 254-267.

138 storage tanks in a chemical plant. Bernechea and Arnaldos Viger (2013) have used a 139 probabilistic approach to assess risk and to optimize the design of storage plants and for 140 minimizing the risk. None of these studies has considered inherent safety measures in their 141 optimization procedure.

142 Medina-Herrera et al. (2014) developed a methodology that can be applied in order to design 143 inherently safer distillation systems. They used the principles of quantitative risk analysis 144 combined with economic objectives for the design of two types of distillation arrangements, 145 namely conventional distillation and multi-effect distillation. However, they didn't present an 146 optimization framework for systematic selection of the optimum design.

147 Since making the processes inherently safer seem to be conflicting with the plant economics in 148 some cases (Medina-Herrera et al., 2014), an optimization framework is required to find an 149 economically inherently safer design.

150 Nowadays, inherent safety has gained acceptance, with law initiatives and is included in codes.

151 Although considering the costs of hazardous accidents an ISD is necessarily the cost-optimal 152 option (CCPS, 2000; Edwards and Lawrence, 1993; Hendershot, 2000; Khan and Amyotte, 153 2002), it requires quantification of safety risks and consequences, in addition to bridging 154 between the incommensurable economic and safety objectives (Medina-Herrera et al., 2014; Eini 155 et al., 2015). In addition, a holistic method is needed that systematically generates alternative 156 solutions and screen the candidate decisions in order to find the optimal solution. Such a 157 framework conforms to optimization programming.

158 Eini et al. (2015) proposed an optimization procedure which integrates both plant economics and 159 accident costs based consequence modeling for different design schemes. They applied the sum 160 of accident costs and processing costs all through the plant lifespan, as the objective function. 
Saeed Eini, Hamid Reza Shahhosseini, Majid Javidi, Mahdi Sharifzadeh, Davood Rashtchian. Inherently safe and economically optimal design using multi-objective optimization: The case of a refrigeration cycle. Process Safety and Environmental Protection, 2016, 104 (Part A), 254-267.

161 They applied consequence modeling and "Probit" function for assessing the costs of the 162 accidents. However, they didn't consider the probability of the accidents. To assess the risk of 163 any accident scenario, it is necessary that the probability of that event and associated 164 consequences be quantified (Javidi et al., 2015).

165 Due to the uncertain nature of accidents, incorporation of accidents costs directly in optimization 166 problems do not necessarily represent the real risk level. The implication is that ISD concepts 167 should be based on a probabilistic approach. Even if the accident risks are fully quantified by a 168 cost function, the probabilistic nature of the frequency and the intensity of the potential accidents 169 makes the economic function highly uncertain. Therefore, in order to underpin a design solution 170 which is inherently safer and economically optimum, the optimization program should minimize 171 risk levels and plant costs simultaneously. In the present research, multi-objective optimization 172 programming is applied in order to quantify the trade-off between the production economy and 173 the costs of accidents. The solution of a multi-objective optimization is not unique but a set of 174 solutions that form a Pareto front. At one extreme, more weight is given to the economic 175 objective. Here, the risks of potential accidents are assumed to be relatively low. On the other 176 extreme, the safety objective is dominant and the risk of accidents is considered to be likely in 177 order to achieve an inherently safer design. Such a Pareto front can quantify the trade-off 178 between the costs of inherently safe design strategies and process profitability and enable 179 decision-maker to underpin a practical compromise.

180 In this paper, a multi-objective optimization (MOO) framework is proposed to optimize 181 simultaneously inherent safety level and plant economic. The applicability of the framework is 182 shown using a case study. To evaluate inherent safety level probabilistic risk analysis is 183 considered which combines accidents costs with the likelihood of accidents occurrence. The 
Saeed Eini, Hamid Reza Shahhosseini, Majid Javidi, Mahdi Sharifzadeh, Davood Rashtchian. Inherently safe and economically optimal design using multi-objective optimization: The case of a refrigeration cycle. Process Safety and Environmental Protection, 2016, 104 (Part A), 254-267.

184 inherent safety strategies are incorporated into the optimization algorithm by considering 185 decision parameters associated with each strategy. The novelties of the present study in comparison to the previous research (Eini et al., 2015) are as follows:

- Multi-objective optimization programming is applied in order to simultaneously optimize

Accidents frequencies have not been considered in the procedure presented by Eini et al. (2015).

195 Their defined objective function comprised of summing plant processing costs and accident costs. Consequently, the optimization procedure concerned finding the optimum design using a 197 single-objective function.

198 Due to the probabilistic nature of the accidents, the consequence modeling results should be 199 corrected by accidents frequencies and accidents occurrence combination to show more realistic 200 risk calculation. Therefore in addition to the plant costs (considering both operating and capital 201 costs) as an objective function, risk can be introduced to the optimization problem as another 202 objective function. According to the different nature of these two objective functions (plant costs 203 and risk), a multi-objective optimization (MOO) problem should be implemented.

204 The outline of the paper is as follows. The present section explored the research background and 205 justified the necessity of the research. Section two discusses the research methodology and 206 presents the formulation of the multi-objective optimization (MOO). In Section three, the case 
Saeed Eini, Hamid Reza Shahhosseini, Majid Javidi, Mahdi Sharifzadeh, Davood Rashtchian. Inherently safe and economically optimal design using multi-objective optimization: The case of a refrigeration cycle. Process Safety and Environmental Protection, 2016, 104 (Part A), 254-267.

207 study is described and the details of risk analysis, as well as the economic objective function, are 208 presented. The results are reported and discussed in Section four. Finally, Section five 209 summarizes the research and concludes the paper.

\section{Methodology: Multi-objective optimization for inherently safer design}

212 To Design a process it is required to consider and to compare all feasible alternatives. These

213 alternatives may differ either in their structure, or operation, or both. Different structural and

214 operational decision variables result in different design alternatives. The final selected design 215 scheme should be economically feasible and be consistent with environmental regulations.

216 Nevertheless, the safety level of a design should be of high standards. Considering risk

217 management strategies in the process design provides the opportunity to enhance the process

218 reliability and reduces the losses associated with potential accidents. Therefore, the aim of the

219 present research is to propose a computational algorithm in which inherent safety criteria are 220 systematically considered in the early design stages. The main parts of the proposed algorithm

221 are shown in Figure 1. They are (I) superstructure constriction and objective function 222 evaluations, (II) multi-objective optimization (MOO), and (III) decision-making. Once a

223 superstructure is developed, the MOO algorithm proposes different values for the decision

224 variables. The fitness of the candidate solution is benchmarked against economic and safety 225 criteria. The output of the MOO algorithm is a set of optimal solutions that forms a Pareto front.

226 Finally, using decision-making tools a single solution that established the trade-off between 227 competing objectives is selected as the optimal design. The details of each of these three 228 calculation steps are discussed in the following. 
Saeed Eini, Hamid Reza Shahhosseini, Majid Javidi, Mahdi Sharifzadeh, Davood Rashtchian. Inherently safe and economically optimal design using multi-objective optimization: The case of a refrigeration cycle. Process Safety and Environmental Protection, 2016, 104 (Part A), 254-267.

( I ) Superstructure construction and objective function evaluation
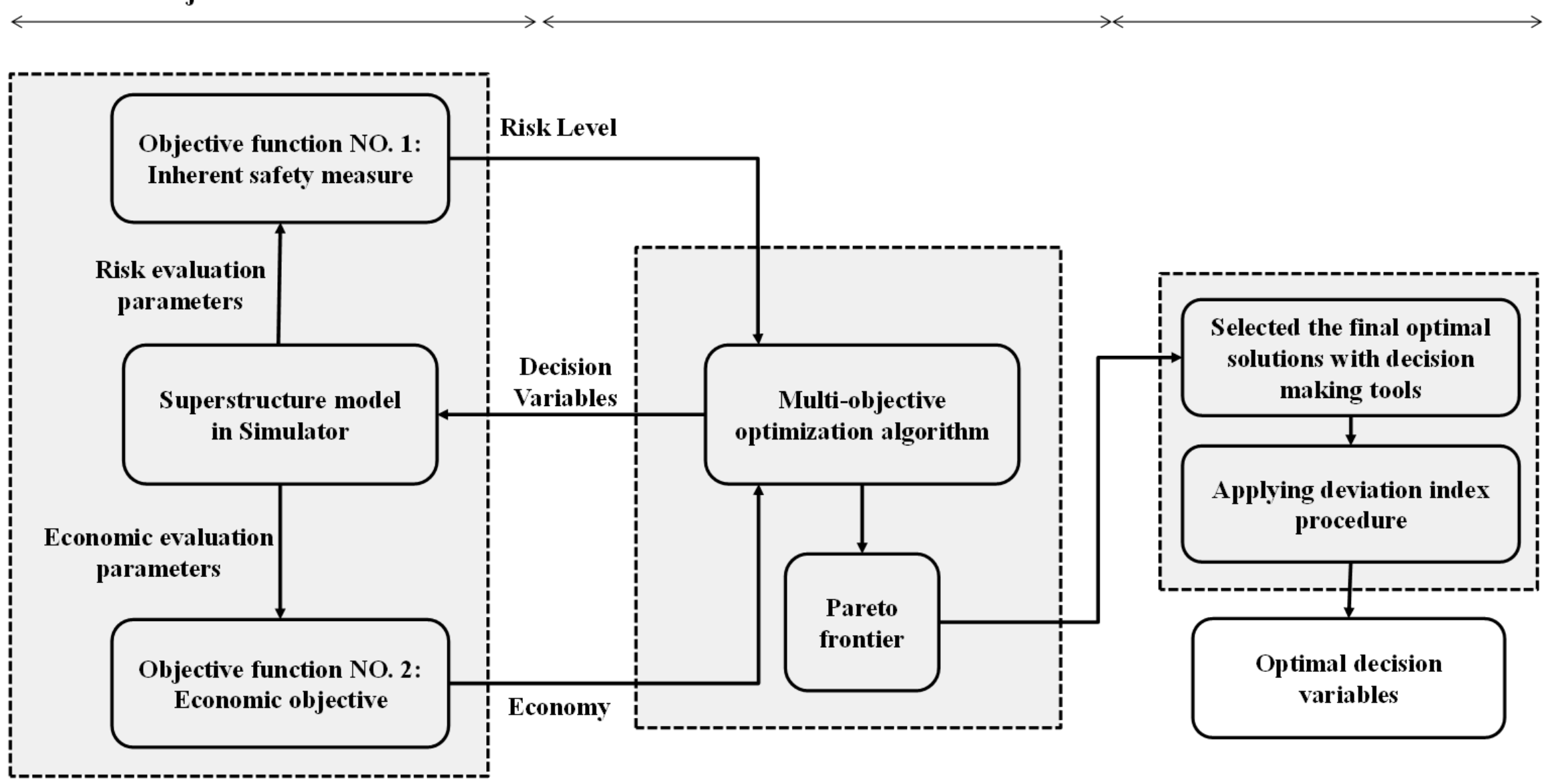

Figure 1 - The general algorithm to select an inherently safer and economically optimal design using multi-objective approach 
Saeed Eini, Hamid Reza Shahhosseini, Majid Javidi, Mahdi Sharifzadeh, Davood Rashtchian. Inherently safe and economically optimal design using multi-objective optimization: The case of a refrigeration cycle. Process Safety and Environmental Protection, 2016, 104 (Part A), 254-267.

\subsection{Superstructure construction and objective function evaluation}

234 The ideal treatment for potential hazards in the first place is to completely remove them.

235 However, there is often a very low chance to make a process absolutely "safe" and the goal of

236 safe process design is to find a configuration that is rather inherently "safer" and more reliable

237 compared to other alternatives. Therefore, the provision of means to control the risk associated

238 with a hazard is very much the second best solution (Mannan, 2013). Inherent safety strategies

239 reduce or permanently eliminate the hazards and guarantee lower risk levels by changing the

240 nature of the process. In order to make a process inherently safe, it is necessary to generate

241 alternative solutions systematically. Afterward, the solutions should be screened based on the

242 desired performance criteria. In the following subsection, the required methods for superstructure

243 construction and evaluation of the objective functions are discussed.

\section{$244 \quad$ 2.1.1. Superstructure construction}

245 To take into account all feasible options, a superstructure should be created which embeds all 246 alternative process configurations, processing technologies and their feasible interconnections

247 (Smith, 2005). Such a superstructure should also include various strategies for enhancing the 248 inherent safety of the process, including substitution, simplification, and minimization, 249 moderation. Examples of such strategies are:

250 - Selection of safer reaction pathways;

251 - Substitution of hazardous energy transfer mediums, solvents, and adsorbents;

252 - Selection of alternative safer process equipment (e.g. reactor type, separation 253 technology);

254 - Moderating processing conditions such as temperature and pressure, or reducing 255 concentration of hazardous materials using inert; 
Saeed Eini, Hamid Reza Shahhosseini, Majid Javidi, Mahdi Sharifzadeh, Davood Rashtchian. Inherently safe and economically optimal design using multi-objective optimization: The case of a refrigeration cycle. Process Safety and Environmental Protection, 2016, 104 (Part A), 254-267.

- Reducing the inventory of hazardous materials

257 The general algorithm to select an inherently safer and economically optimal design (ISEOD) 258 using multi-objective approach is shown in Figure 1.

\section{2.1.2. Objective functions}

260 The two objective functions that should be considered in order to develop an ISEOD are inherent 261 safety measure as well as an economic objective. The economic objectives can be expressed 262 using one of the common methods: total annualized cost, capitalized cost, net present value, and

263 so on. In addition, layout optimization considering land cost as well as safe distances between 264 plant elements may be required. Besides, in order to measure the inherent safety level of a 265 process plant, risk level calculated using quantitative risk assessment (QRA) can be utilized. 266 Nowadays, QRA has become an efficient tool in decision-making to evaluate the risk level. QRA

267 procedure is carried out in several stages: (i) Hazardous scenario selection, (ii) Frequency 268 estimation, (iii) Consequence modeling, and (iv) Risk level calculation. These stages are 269 discussed in the following.

270 (i) Hazardous scenario selection:

271 The first stage of the QRA procedure is hazardous scenario selection. For this purpose, all 272 necessary data such as environmental conditions, physical and chemical specification, and 273 process specifications must be collected. Afterward, the potential sources of the hazards which 274 can lead to an accident in the plant are selected as the accident scenarios.

275 (ii) Frequency estimation:

276 When the accident scenarios are selected, the second stage of QRA procedure is scenarios 277 frequency estimation. A method for estimating the accident frequencies is event tree analysis 278 (ETA) (Casal, 2008). Having the frequency of a release (as the initial event in each accident 
Saeed Eini, Hamid Reza Shahhosseini, Majid Javidi, Mahdi Sharifzadeh, Davood Rashtchian. Inherently safe and economically optimal design using multi-objective optimization: The case of a refrigeration cycle. Process Safety and Environmental Protection, 2016, 104 (Part A), 254-267.

279 scenario), Event Tree is applied for calculating the frequency of final possible outcomes. For

280 example, upon a flammable chemical release, the potential outcomes can be a pool fire, a jet fire,

281 vapor cloud explosion (VCE), vapor cloud fire (VCF) and boiling liquid expanding vapor

282 explosion (BLEVE). Two ways can be applied in order to estimate the frequency of an initial

283 event. They are fault tree analysis (FTA) or using failure frequency databanks (Casal, 2008).

284 Failure frequency databanks are constructed based on past accident records. There are several 285 databanks available such as API (2008), OGP (2010), and Handbook of failure frequencies

286 (LNE, 2009).

287 (iii) Consequence modeling:

288 Consequence modeling is the third step in the QRA approach. The outputs of this stage are the 289 effects associated with accidents on people, equipment, environment, and so on. Consequence 290 modeling is supposed to be carried out in several steps to model the effects of various scenarios.

291 First, source modeling is performed that provides discharge rate and the total discharged volume 292 over a time horizon. Dispersion modeling is subsequently used in order to describe how the 293 hazardous material is dispersed to certain concentration levels. Then, fire and explosion models

294 convert the dispersion model information into hazard potentials such as thermal radiation and 295 blast overpressure. Consequently, using appropriate effect modeling, the number of individuals 296 affected and the property damage can be calculated. Finally, using of individuals affected and the 297 property damage, and associated costs, the total imposed costs of any accident scenario can be 298 obtained.

299 (iv) Risk level calculation: 
Saeed Eini, Hamid Reza Shahhosseini, Majid Javidi, Mahdi Sharifzadeh, Davood Rashtchian. Inherently safe and economically optimal design using multi-objective optimization: The case of a refrigeration cycle. Process Safety and Environmental Protection, 2016, 104 (Part A), 254-267.

300 The final stage of the QRA is risk level calculation. The general expression to calculate the risk

301 level associated with an accident scenario $\left(R_{i}\right)$ imposed to a risk receptor can be shown as

302 follows (CCPS, 2000).

$R_{(x, y)_{i}}=f_{i} \times C_{(x, y)_{i}}$

303 Where $i$ refers to the accident scenario, $f$ is the scenario frequency, $C$ is the scenario

304 consequence, and $(x, y)$ represents the risk receptor location.

305 Based on Equation (1), the risk level associated with all scenarios in the $(x, y)$ location can be 306 represented as Equation (2).

$R_{(x, y)}=\sum_{i} f_{i} \times C_{(x, y)_{i}}$

307 Finally, the risk level imposed to all risk receptors can be calculated using Equation (3).

Risk level $=\sum_{(x, y)} R_{(x, y)}$

\subsection{Multi-objective optimization procedure}

309 Simultaneous consideration of process economy and the level of inherent safety using 310 mathematical programming conforms to multi-objective optimization. A multi-objective

311 optimization program consisted of several competing objectives as follows:

Optimize $\left\{f_{1}(\vec{x}), \ldots, f_{k}(\vec{x})\right\}$

Subject to $x \in S$

312 Here, the instances of the economic objectives are the capital investment required for purchasing

313 process equipment, operating costs, raw material costs. Often capital and operating costs are

314 aggregated based on the plant lifespan for example in terms of total annualized costs. The

315 quantification of the level of inherent process safety was discussed in subsection 2.1.2. In the 
Saeed Eini, Hamid Reza Shahhosseini, Majid Javidi, Mahdi Sharifzadeh, Davood Rashtchian. Inherently safe and economically optimal design using multi-objective optimization: The case of a refrigeration cycle. Process Safety and Environmental Protection, 2016, 104 (Part A), 254-267.

316 Optimization problem (Equation (4)), $\mathrm{x}$ is a vector of decision variables. Examples of decision

317 variables include process configuration, equipment design, process inventory, and process

318 operating conditions. The decision variable can be decided within a range of feasible candidates

$319 \mathrm{~S} \subset \mathrm{R}^{\mathrm{n}}$ which include alternative process configurations, practical size of equipment, and the safe

320 operating conditions.

321 In multi-objective optimization problems, the optimal solution is not unique, but compromises a

322 Pareto front or Pareto set. For a given solution on the Pareto front, it is not possible to improve

323 an objective function without compromising other objective functions. For the case of

324 simultaneous optimization of economic and inherent safety, such a Pareto front represent the best

325 comprise that can be reached among these competing objectives. In other words, if further

326 improvement is desired in the level of process safety, more investment is required. Conversely, if

327 further economic saving is needed, the designer should make sure that the safety will not be

328 compromised. The ideal solution vector $F^{\text {ideal }}$ and a non-ideal solution

329 vector $\mathrm{F}^{\text {non-ideal }}$ represent the upper and lower bounds for the objective function values of the

330 Pareto optimal solutions, respectively (Gebreslassie et al., 2009; Konak et al., 2006; Madetoja et

331 al., 2008). Figure 2 displays Pareto front, ideal and non-ideal solutions for four possible

332 combinations of the minimization and maximization procedures. The solid curve marks the

333 Pareto optimal solution set. In the algorithm proposed in this paper (Figure 1), there are two

334 objective functions: $f_{1}(\vec{x})$ : Total annualized costs and $f_{2}(\vec{x})$ : Plant risk level which both should be

335 minimized. Therefore it is expected that the Pareto front matches the figure shown in case (a).

336 With respect to this case, the ideal solution is the point in which the risk level, as well as the total

337 annualized costs, have their minimal values. However, this ideal solution cannot be reached in 338 reality. 
Saeed Eini, Hamid Reza Shahhosseini, Majid Javidi, Mahdi Sharifzadeh, Davood Rashtchian. Inherently safe and economically optimal design using multi-objective optimization: The case of a refrigeration cycle. Process Safety and Environmental Protection, 2016, 104 (Part A), 254-267.

339 Subsection 2.2.1 describes the multi-objective optimization algorithm used in this paper in order 340 to generate the Pareto front.

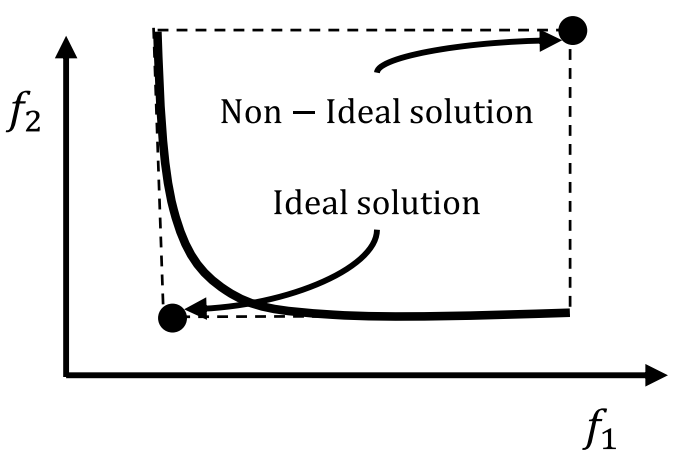

Case (a): Minimize $\mathrm{f}_{1}$, Minimize $\mathrm{f}_{2}$

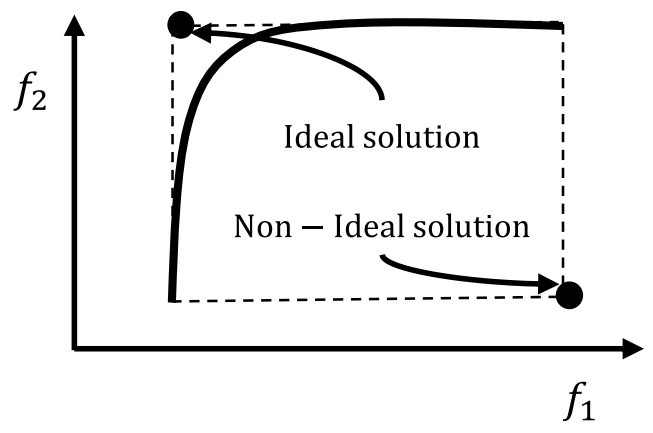

Case (b): Minimize $f_{1}$, Maximize $f_{2}$

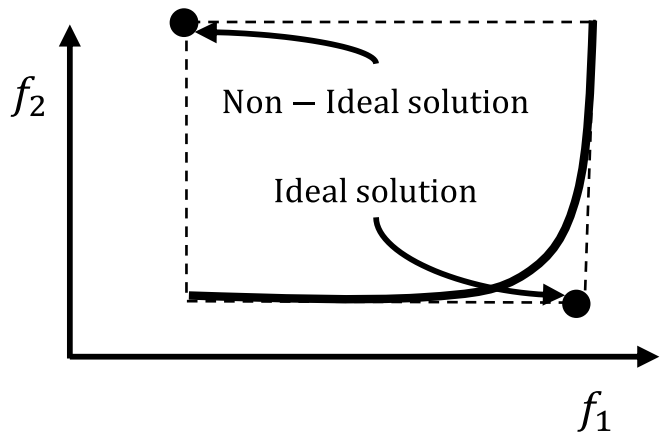

Case (c): Maximize $f_{1}$, Minimize $f_{2}$ 
Saeed Eini, Hamid Reza Shahhosseini, Majid Javidi, Mahdi Sharifzadeh, Davood Rashtchian. Inherently safe and economically optimal design using multi-objective optimization: The case of a refrigeration cycle. Process Safety and Environmental Protection, 2016, 104 (Part A), 254-267.

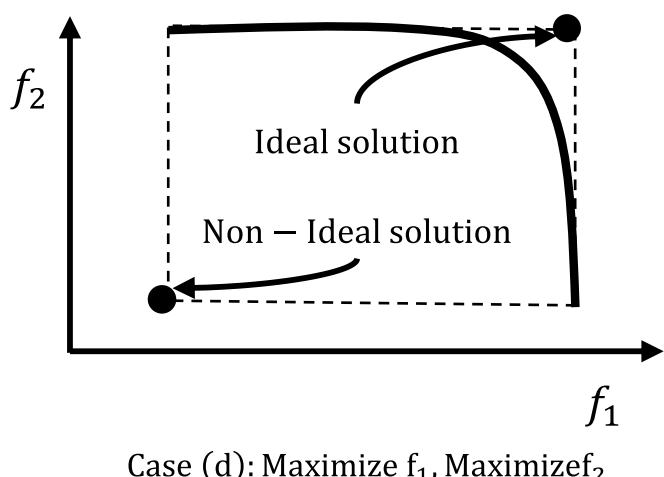

Figure 2 - Pareto set for four combinations of two types of objectives

347 2.2.1. Visualizing the Pareto furniture, Non-dominated sorting genetic algorithm (NSGA-

348 II)

349 In this study, NSGA-II algorithm which was introduced by Deb (Deb, 2005) is utilized as a multi-

350 objective optimization method in order to find the optimal Pareto set and the corresponding

351 Pareto front. Deb investigated the simulation outcomes from a number of difficult problems and

352 concluded that NSGA-II outperforms two other contemporary multi-objectives evolutionary

353 algorithms (EAs) (Pareto-archived evolution strategy (PAEs) and strength Pareto EA (SPEA))

354 (Knowles and Corne, 1999) in terms of finding a diverse set of solutions and in converging

355 near the appropriate Pareto optimal set. According to Figure 3, NSGA-II as an Elite-preserving

356 technic and an explicit diversity-preserving structure can be depicted through the seven steps (Li

357 et al., 2015). 
Saeed Eini, Hamid Reza Shahhosseini, Majid Javidi, Mahdi Sharifzadeh, Davood Rashtchian. Inherently safe and economically optimal design using multi-objective optimization: The case of a refrigeration cycle. Process Safety and Environmental Protection, 2016, 104 (Part A), 254-267.

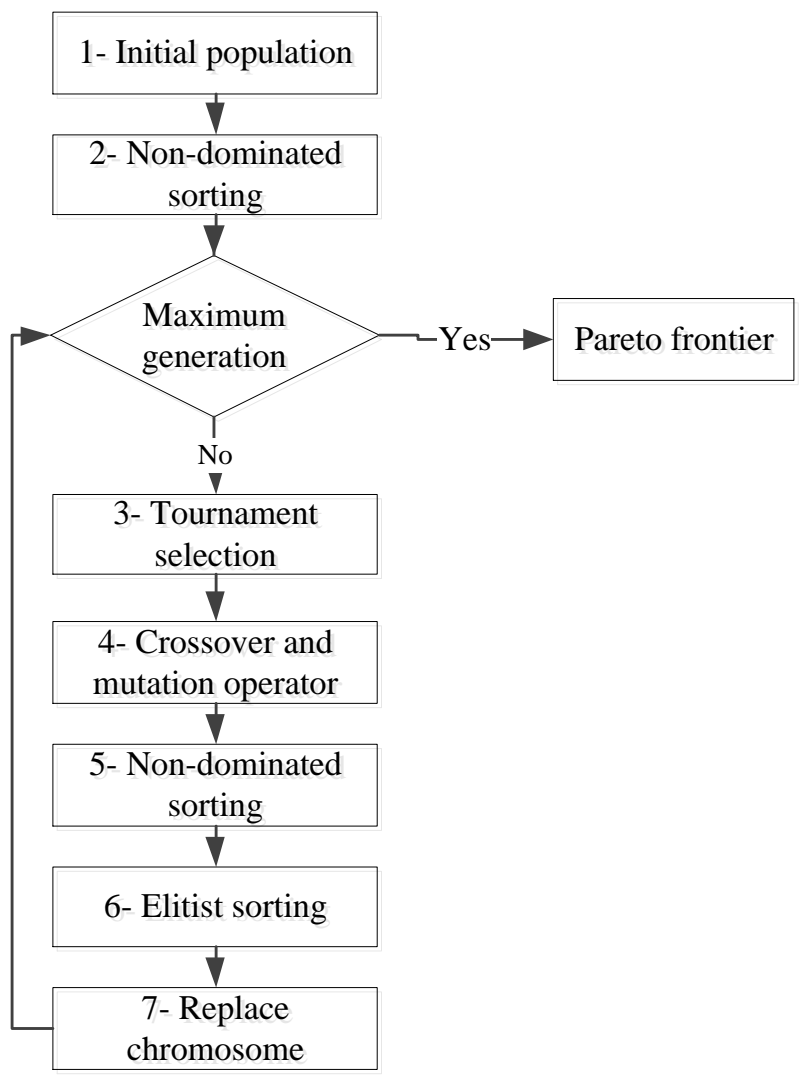

Figure 3 - Flow chart of NSGA-II algorithm

360 In an evolutionary cycle of NSGA-II, initially, a random parent population is generated. The

361 population is sorted based on the non-domination procedure (rank and crowding distance).

362 Parent selection for crossover and mutation operation is performed based on the tournament

363 selection. In the next step, crossover and mutation are used to generate the child populations.

364 Then all previous and current population members are integrated together to create a combined

365 population, then the population is sorted according to non-domination. Since all previous and

366 current population members are included in combined population, the elitism is insured. It means

367 that solutions with better fitness are chosen by elitist sorting and these become the parent

368 individuals. These steps are repeated until the maximum generation number is reached and

369 Pareto front developed. 
Saeed Eini, Hamid Reza Shahhosseini, Majid Javidi, Mahdi Sharifzadeh, Davood Rashtchian. Inherently safe and economically optimal design using multi-objective optimization: The case of a refrigeration cycle. Process Safety and Environmental Protection, 2016, 104 (Part A), 254-267.

370 All of the point on the Pareto front can be a candidate for the optimal solution. Therefore, to 371 select a single point on the Pareto front, a decision-making tool is needed. Subsection 2.3

372 presents the basic concepts of two well-known decision-making methodologies.

373

\subsection{Decision-making on multi-objective optimization}

375 In multi-objective optimization problems, all the points on the Pareto set are optimal solution 376 with different weights to various objective values. However, in the practical point of view, only 377 one optimal solution should be chosen. In this paper most well-known and the common type of 378 decision-making processes including the LINMAP and TOPSIS methods are applied in parallel

379 in order to specify the final optimal solution. TOPSIS estimates the alternatives adoptability 380 according to their distance with the ideal and the non-ideal points. Meanwhile, LINMAP method 381 follows the nearest alternative to the ideal point. The following sections are presented here in 382 order to describe these decision-making algorithms.

383 2.3.1. LINMAP decision-making (Linear Programming Technique for Multidimensional 384 Analysis of Preference) (Yu, 2013)

385 The distance of every solution on the Pareto front from the ideal solution marked by $\mathrm{d}_{\mathrm{i}+}$ is 386 defined as:

$d_{i+}=\sum_{j=1}^{m}\left(F_{i j}-F_{j}^{i d e a l}\right)^{2} \quad i=1, \ldots, n$

387 Where $F_{j}^{i d e a l}$ is the ideal solution of the $j$ th objective in a single-objective optimization. In the 388 LINMAP decision-making, the solution with minimum distance from the ideal point is selected 389 as a final desired optimal solution. 
Saeed Eini, Hamid Reza Shahhosseini, Majid Javidi, Mahdi Sharifzadeh, Davood Rashtchian. Inherently safe and economically optimal design using multi-objective optimization: The case of a refrigeration cycle. Process Safety and Environmental Protection, 2016, 104 (Part A), 254-267.

2.3.2. TOPSIS decision-making (Technique for Order Preference by Similarity to an Ideal

Solution) (Yue, 2011)

Besides the ideal solution, the non-ideal solution is considered in TOPSIS decision-making.

393 Therefore, besides the distance of each solution from ideal solution $\mathrm{d}_{\mathrm{i}+}$, the distance of each

394 solution from the non-ideal solution denoted $\mathrm{d}_{\mathrm{i}}$ - is implemented as a criterion for the selection of

395 final optimal solution:

$d_{i-}=\sum_{j=1}^{m}\left(F_{i j}-F_{j}^{\text {non-ideal }}\right)^{2} \quad i=1, \ldots, n$

396 A new assessment parameter is defined as follows:

$Y_{i}=\frac{d_{i-}}{d_{i+}+d_{i-}}$

397 In TOPSIS decision-making, a solution with maximum $Y_{i}$ is selected as a desired final solution.

398 In order to explore the reasonable status of various solutions obtained using above-mentioned 399 tools, the deviation index of each solution from the ideal solution is calculated as Equation (8).

$$
d=\frac{\sqrt{\sum_{j=1}^{m}\left(F_{j}-F_{j}^{i d e a l}\right)^{2}}}{\sqrt{\sum_{j=1}^{m}\left(F_{j}-F_{j}^{i d e a l}\right)^{2}}+\sqrt{\sum_{j=1}^{m}\left(F_{j}-F_{j}^{\text {non-ideal }}\right)^{2}}}
$$

\section{Case Study}

402 Vapor-compression refrigeration systems are used in the many types of the industrial plants for 403 separation purposes or chemical storage at low temperatures. It is very common to use

404 hydrocarbons as the refrigerant in gas and petroleum processing plants with respect to the 405 availability of hydrocarbons. However, hydrocarbons have a great flammability hazard potential.

406 Nevertheless, due to the usually high power demand of the compressors (Sharifzadeh et al., 
Saeed Eini, Hamid Reza Shahhosseini, Majid Javidi, Mahdi Sharifzadeh, Davood Rashtchian. Inherently safe and economically optimal design using multi-objective optimization: The case of a refrigeration cycle. Process Safety and Environmental Protection, 2016, 104 (Part A), 254-267.

407 2011), refrigeration cycle shares great costs in a plant. Therefore, the optimal design of this 408 particular unit, in terms of both economic and safety, is very important.

409 In the present study, the case of a pre-cooling natural gas using single refrigerant propane cycle 410 is considered, (Manning and Thompson, 1991). Figure 4 shows the process flow diagram. The 411 cycle consists of two compressions stages and aims at cooling dry natural gas down to $-13.2{ }^{\circ} \mathrm{C}$.

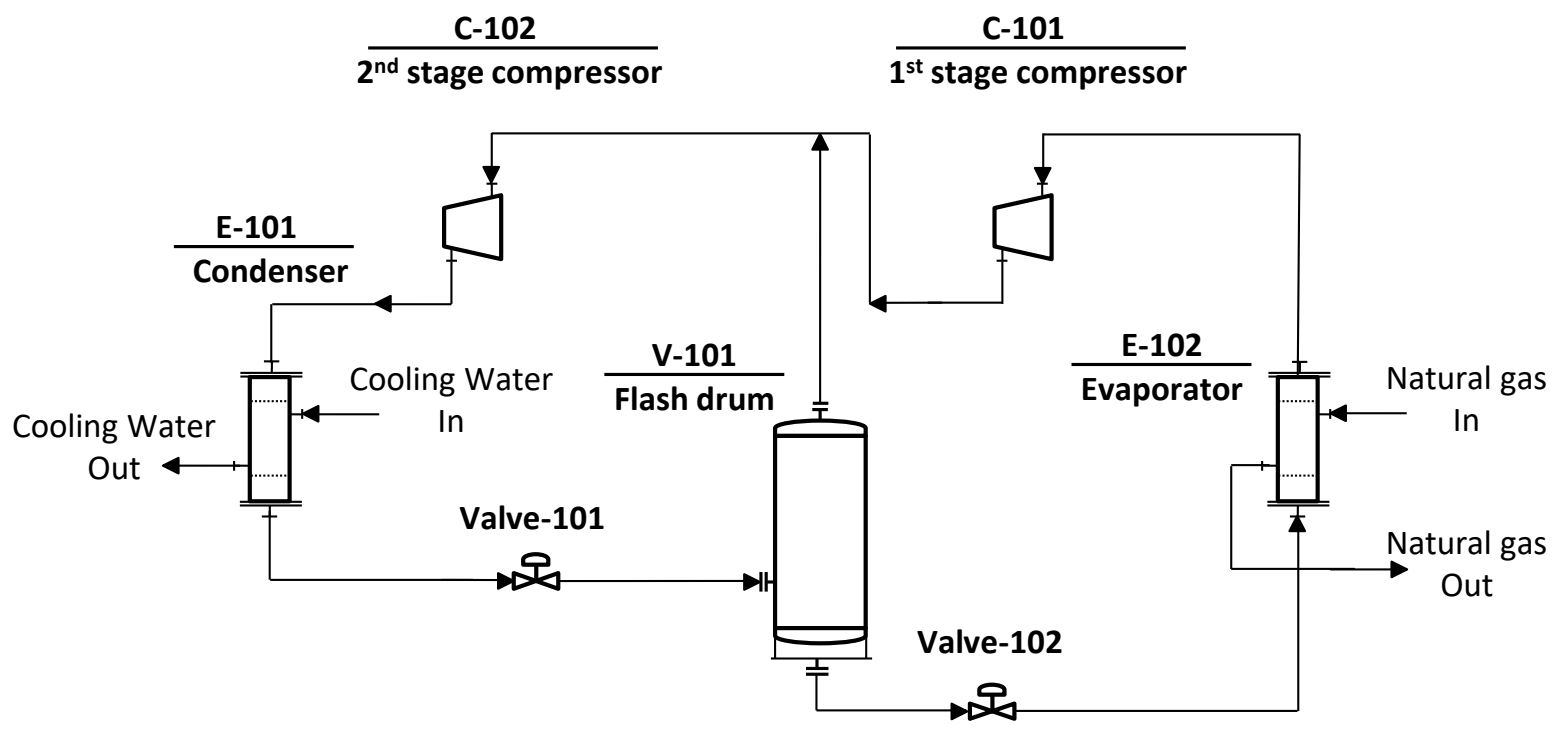

Figure 4 - Simple Refrigeration Cycle

414 The optimal operating pressure of the flash drum in the propane refrigeration cycle can be 415 estimated as following (Manning and Thompson, 1991):

$$
P_{\text {econ }}=P_{c h}\left(P_{\text {cond }} / P_{c h}\right)^{0.614}
$$

Where: $\mathrm{P}_{\mathrm{econ}}=$ optimum drum operating pressure, $\mathrm{kPa}$

$$
\begin{aligned}
& \mathrm{P}_{\mathrm{ch}}=\text { chiller (evaporator) pressure, } \mathrm{kPa} \\
& \mathrm{P}_{\text {cond }}=\text { condenser pressure, } \mathrm{kPa}
\end{aligned}
$$

416 For the cycle under study, cooling water (entering and leaving the condenser at $25^{\circ} \mathrm{C}$ and $30^{\circ} \mathrm{C}$, 417 respectively) is used as the coolant in the condenser. A typical approach temperature of $5{ }^{\circ} \mathrm{C}$ is 418 used for both the condenser and the evaporator (Smith, 2005). Consequently, the temperature of 
Saeed Eini, Hamid Reza Shahhosseini, Majid Javidi, Mahdi Sharifzadeh, Davood Rashtchian. Inherently safe and economically optimal design using multi-objective optimization: The case of a refrigeration cycle. Process Safety and Environmental Protection, 2016, 104 (Part A), 254-267.

419 the propane in the condenser and evaporator is $35{ }^{\circ} \mathrm{C}$ and $-18.2{ }^{\circ} \mathrm{C}$, respectively. The saturation 420 pressure of propane in these temperature levels is $1234 \mathrm{kPa}$ for the condenser and $260 \mathrm{kPa}$ for

421 the evaporator. Using Equation (9) the optimal operating pressure of the drum is equal to 676 $422 \mathrm{kPa}$.

423 The cycle with above-mentioned specification is considered as a base-case in this paper. The 424 optimum pressure calculated by Equation (9) may not be the optimal value if one considers both 425 economic and safety aspects. Therefore, drum operating pressure is one of the decision variables.

426 One of the principal ways to make a process inherently safer is to limit the inventory of 427 hazardous material. It is better to have only a small inventory of hazardous material rather than a 428 large one which needs highly engineered safety systems. Thus, according to the minimization 429 strategy of inherent safety, the number of parallel paths (NPPs) of pressure drop, shown in 430 Figure 5, also can be a decision variable. Because increasing the NPP reduces the refrigerant rate 431 in each path and consequently, the size of the drum and the refrigerant inventory of the drum will 432 be smaller. The NPP as a structural variable is determined in the superstructure. The 433 superstructure which is used in the present study is shown schematically in Figure 5 (Eini et al., 434 2015). The lower and upper bound values of drum operating pressure are considered to be 300 $435 \mathrm{kPa}$ and $1200 \mathrm{kPa}$, respectively. These ranges of operating pressures are selected according to the 436 saturation temperature of the propane refrigerant in the condenser and evaporator. Also, it is 437 assumed that NPP can have the values in the range of 1 to 20. 
Saeed Eini, Hamid Reza Shahhosseini, Majid Javidi, Mahdi Sharifzadeh, Davood Rashtchian. Inherently safe and economically optimal design using multi-objective optimization: The case of a refrigeration cycle. Process Safety and Environmental Protection, 2016, 104 (Part A), 254-267.

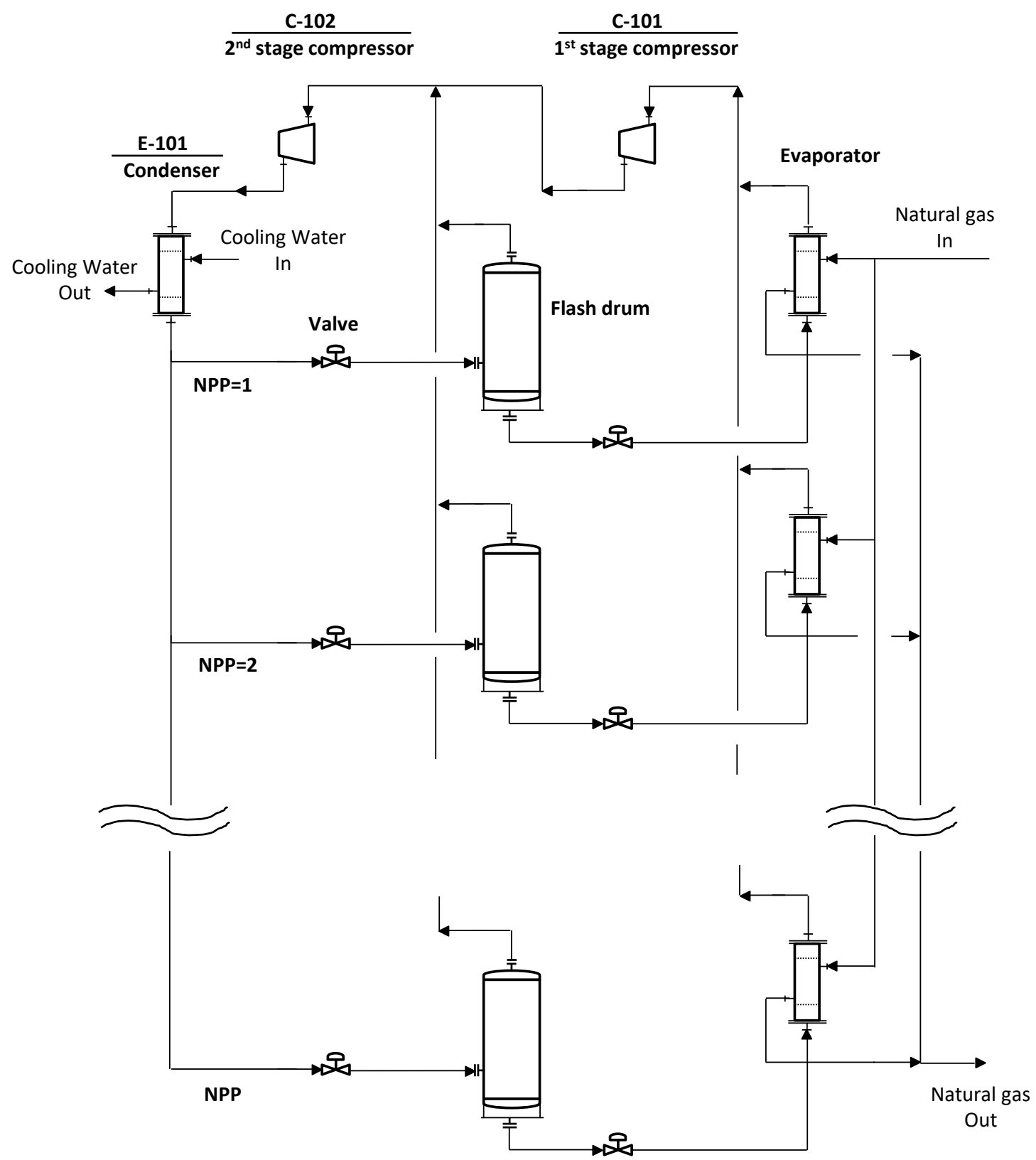

Figure 5 - Intended superstructure of refrigeration cycle

440 Making the plant inherently safer and economically more profitable are the two objectives of the

441 present research. Here, the plant risk level is chosen as the first objective function for the plant

442 inherent safety. In subsection 3.1 the methodology applied for calculating the risk level is 
Saeed Eini, Hamid Reza Shahhosseini, Majid Javidi, Mahdi Sharifzadeh, Davood Rashtchian. Inherently safe and economically optimal design using multi-objective optimization: The case of a refrigeration cycle. Process Safety and Environmental Protection, 2016, 104 (Part A), 254-267.

443 discussed in more detail. Furthermore, subsection 3.2 presents the details of the economic 444 objective function. Afterward, the optimization procedure is presented in subsection 3.3.

$446 \quad$ 3.1. Risk analysis

447 The failures of vessels and columns account for $21 \%$ of accidents in refineries, (CCPS 2003).

448 Since in the present case study (Figure 5) the largest material inventory is located in the flash

449 drums, this paper focuses on the drum(s) as hazard source(s).

450 In the present research, it is assumed that the phenomena of boiling liquid expanding vapor 451 explosion (BLEVE) occurs during the accident, in which a sudden loss of containment of a 452 pressure vessel (containing a superheated liquid or liquefied gas) occurs due to the explosion.

453 The release of hazardous material is assumed to be followed by a fireball that consumes all of the 454 released material. Since the propane refrigerant is a flammable material, the consequence of the 455 combustion of the entire contents of hazardous materials in the release point is worse than any 456 dispersion scenario. Therefore, a design based on BLEVE is more conservative than any other 457 scenario and is in fact, the worst-case scenario. Consequences of this type of accidents can be 458 very severe, especially in areas close to the release point (CCPS, 2000). It should be noted that 459 for the case of toxic materials (e.g., ammonia, or chlorine), the dispersion may represent more 460 hazard and need to be fully modeled.

461 In this study, different potential damage receptors were supposed:

$462 \quad-80$ operators in the surrounding area (in $130 \mathrm{~m}$ radius).

463 - 8 buildings (B4-Type according to API (1995) definition) at a distance of $300 \mathrm{~m}$ 464 downwind; each building has four occupants. 
Saeed Eini, Hamid Reza Shahhosseini, Majid Javidi, Mahdi Sharifzadeh, Davood Rashtchian. Inherently safe and economically optimal design using multi-objective optimization: The case of a refrigeration cycle. Process Safety and Environmental Protection, 2016, 104 (Part A), 254-267.

465 The meteorological data of the region in the present study comprising temperature, humidity, 466 atmospheric stability class, and wind velocity, are very important to consequence modeling and 467 for QRA procedure (Table 1).

Table 1 - Metrological data of the region

\begin{tabular}{cc}
\hline Ambient temperature & $30{ }^{\circ} \mathrm{C}$ \\
Ambient pressure & $1 \mathrm{bar}$ \\
Ambient relative humidity & $40 \%$ \\
Class stability & $\mathrm{F}$ \\
Wind speed & $1.5 \mathrm{~m} / \mathrm{s}$ \\
\hline
\end{tabular}

470 3.1.1. Frequency estimation:

471 Table 2 displays some generic frequency data for pressure vessels (LNE, 2009). According to 472 this table, the release frequency for the selected scenario (catastrophic rupture of the drums) is 473 equal to 5E-5.

Table 2 - Frequency data (LNE, 2009)

\begin{tabular}{cc}
\hline Loss of equipment event & Frequency(year-1) \\
\hline Catastrophic rupture & $5 \times 10^{-5}$ \\
Large breach & $2.2 \times 10^{-3}$ \\
Medium breach & $2.2 \times 10^{-3}$ \\
\hline
\end{tabular}

According to the BEVI guide (2009), for the medium size instantaneous spill, the probability of BLEVE/fireball is $50 \%$ among all outcomes. This probability is calculated by the product of the

479 probability of immediate ignition rather than non-immediate ignition and probability of BLEVE/fireball rather that explosion. Therefore, the frequency of a BLEVE/fireball outcome can be calculated using Equation (10): 
Saeed Eini, Hamid Reza Shahhosseini, Majid Javidi, Mahdi Sharifzadeh, Davood Rashtchian. Inherently safe and economically optimal design using multi-objective optimization: The case of a refrigeration cycle. Process Safety and Environmental Protection, 2016, 104 (Part A), 254-267.

$$
\begin{aligned}
f_{\text {BLEVE/FIREBALL }} & =f_{\text {leak/rupture }} \times\left(P_{\text {immediate ignition }} \times P_{B L E V E / \text { fireball }}\right) \\
& =\left(5 \times 10^{-5}\right) \times(0.50)=2.45 \times 10^{-5} \text { year }^{-1}
\end{aligned}
$$

\subsubsection{Consequence analysis:}

484 There are several damages such as loss of human life, structural damages and environmental 485 damages related to accidents. In this study loss of human life, human injuries and structural 486 damages are considered as the accidents consequences.

487 To model the consequences of the selected scenarios, it should be noted that a BLEVE has 488 various effects; fireball is the important effect for flammable release materials. The combined 489 action of BLEVE and fireball can be summarized as the following effects:

$490 \quad$ - Blast wave

491 - Thermal radiation

492 For these outcomes, detailed procedure to model the consequences has been presented by Eini et 493 al. (2015). The applied consequence modeling has two features. The explosion severity is 494 calculated based on the TNT equivalence indicator (Casal, 2008), which is used in order to 495 quantify the severity of overpressure conditions produced under boiling liquid expanding vapor 496 explosion (BLEVE) conditions. The potential for fire damage is quantified in terms of fireball 497 duration and thermal radiation, using the source point method (Casal, 2008). Then, the Probit 498 analysis is applied in order to relate the overpressure and fire effects , to the probability of 499 damages for any of the above mentioned vulnerable elements in specified distances. Therefore, 500 the outdoor fatality and injuries due to overpressure and thermal radiation, as well as the 501 damages to buildings (either collapse or major structural damage) due to overpressure, are 
Saeed Eini, Hamid Reza Shahhosseini, Majid Javidi, Mahdi Sharifzadeh, Davood Rashtchian. Inherently safe and economically optimal design using multi-objective optimization: The case of a refrigeration cycle. Process Safety and Environmental Protection, 2016, 104 (Part A), 254-267.

502 calculated using appropriate Probit models. Finally, by using the following items, the total 503 accident costs can be estimated:

504 - The percentage of collapsed buildings

505 - The percentage of buildings which receive major structural damage

506 - The number of fatalities

507 - The number of injuries

508 The building cost has been considered to be $100 \%$ of the cost of the building in the case of 509 collapse and 70\% for major structural damage (Medina et al., 2009).

510 Finally, the total cost of the accident $\left(\mathrm{C}_{\text {total }}\right)$ can be calculated summing the cost imposed to each

511 vulnerable element. In other words, the accident cost is expressed as Equation (11):

$$
\begin{aligned}
C_{\text {total }}= & (\text { number of fatalities } * \text { cost of a fatality }) \\
& +(\text { number of injuries } * \text { cost of an injury }) \\
& +(\text { number of collapsed building } * \text { cost of a building }) \\
& +(\text { number of damaged building } * 70 \% \text { of the cost of a building })
\end{aligned}
$$

512 Table 3 shows the cost data that have been used in the consequence modeling.

Table 3 - Cost data (Eini et al., 2015)

\begin{tabular}{cc}
\hline Cost parameters & Cost $(\$)$ \\
\hline Cost of a fatality & 350,000 \\
Cost of an injury & 160,000 \\
Cost of one building & 100,000
\end{tabular}

\section{3.1.3. Risk level calculation:}

516 As it is shown in Figure 5 the superstructure consists of several drums in parallel. Consequently, 517 it is possible that a number of drums prone to the similar accident at the same time. Therefore, 
Saeed Eini, Hamid Reza Shahhosseini, Majid Javidi, Mahdi Sharifzadeh, Davood Rashtchian. Inherently safe and economically optimal design using multi-objective optimization: The case of a refrigeration cycle. Process Safety and Environmental Protection, 2016, 104 (Part A), 254-267.

518 the general equation that determines the risk should be expanded to consider all of the scenario 519 combinations to obtain the realistic results.

520 The risk associated with the simultaneous explosion of " $\mathrm{n}_{\mathrm{f}}$ " drums in terms of its probability and

521 financial consequence can be calculated as:

$R_{n f}=n_{f} \times C_{\text {total }} \times P_{n f} \times f_{B L E V E / F I R E B A L L}$

522 In the above equation, $\mathrm{C}_{\text {total }}$ is the total cost of the accident and $\mathrm{P}_{\mathrm{nf}}$ is the probability of 523 occurrence of this accident as an independent event (Equation (13)).

$P_{n f}=\left(\frac{1}{n}\right)^{n_{f}}$

524 The number of accident combinations that can occur when $\mathrm{n}_{\mathrm{f}}$ units suffer an occurrence out of

525 " $\mathrm{n}$ " (the total number of drums in the cycle) is calculated as the Equation (14):

$c_{n}^{n_{f}}=\frac{n !}{n_{f} !\left(n-n_{f}\right) !}$

526 Finally, overall risk ( $\mathrm{R}_{\text {overall, }}$ as the second objective function to be optimized) can be expressed

527 as Equation (15):

$R_{\text {overall }}=\sum_{n_{f}=1}^{n} c_{n}^{n_{f}} \times\left(n_{f} \times C_{\text {total }}\right) \times P_{n f} \times f_{B L E V E / F I R E B A L L}$

529 3.2. Economic Objective function

530 As mentioned earlier, the refrigeration cycle shown in Figure 5 includes four major elements: (i)

531 compressor, (ii) condenser, (iii) evaporator, and (iv) flash drum. Consequently, the costs

532 associated with these elements are as follows:

533 - Purchasing cost and energy cost of the compressors.

534 - Purchasing cost and energy cost of the condenser. 
Saeed Eini, Hamid Reza Shahhosseini, Majid Javidi, Mahdi Sharifzadeh, Davood Rashtchian. Inherently safe and economically optimal design using multi-objective optimization: The case of a refrigeration cycle. Process Safety and Environmental Protection, 2016, 104 (Part A), 254-267.

- Purchasing cost of the evaporators(s).

- Purchasing cost of the flash drum(s).

The methods applied for designing and sizing process equipment were adopted from Towler and Sinnott (2008). Also, the cost estimation methods were taken from Seider et al. (2009). Other costs included the instrumentation and piping as well as land-use costs. Instrumentation cost was estimated to be 10 percent of the total plant investment cost (Perry, 1950). The piping cost was considered to be $86.3 \$ / \mathrm{m}$ (Han et al., 2013). The land-use cost depends on the plant location and may vary case by case. In this paper, the value of $100 \$ / \mathrm{m}^{2}$ was considered.

The total annualized cost (TAC) was considered as the economic objective function. The TAC includes the capital costs of procurement and the installation of process equipment and costs associated with the operation of the refrigeration cycle.

$$
T A C=\text { Annualized cost of the investment }+ \text { annual operating costs }
$$

For this purpose, the investment cost (such as the purchasing cost of the equipment and land cost) should be annualized using capital recovery factor (CRF) (Peters et al., 2003). In this paper, the annual interest rate and the plant life time are considered as $18 \%$ and 15 years respectively. In the present study, the number of parallel paths (NPP) was being optimized which affects the required land area. For a plant consisting of $m \times n$ flash drum $(\mathrm{NPP}=m \times n)$, the layout is shown in Figure 6. Here, "a" and "b" are the length and the width of the plant, respectively. The parameter " $d$ " as shown in this figure is the safe distance between two flash drums. This parameter is determined using consequence modeling and is based on the maximum heat flux that reaches the nearby vessels through radiation upon the evaporation of the total material inventory and fire accident. According to General Specification for safety GS 253 (TOTAL, 2012), the radiation level of $9.5 \mathrm{~kW} / \mathrm{m}^{2}$ can be considered conservatively. Therefore, for the case 
Saeed Eini, Hamid Reza Shahhosseini, Majid Javidi, Mahdi Sharifzadeh, Davood Rashtchian. Inherently safe and economically optimal design using multi-objective optimization: The case of a refrigeration cycle. Process Safety and Environmental Protection, 2016, 104 (Part A), 254-267.

557 study in this paper, a fire (flash fire) consequence modeling was performed in order to determine 558 the safe distances of the flash drums (Casal, 2008).

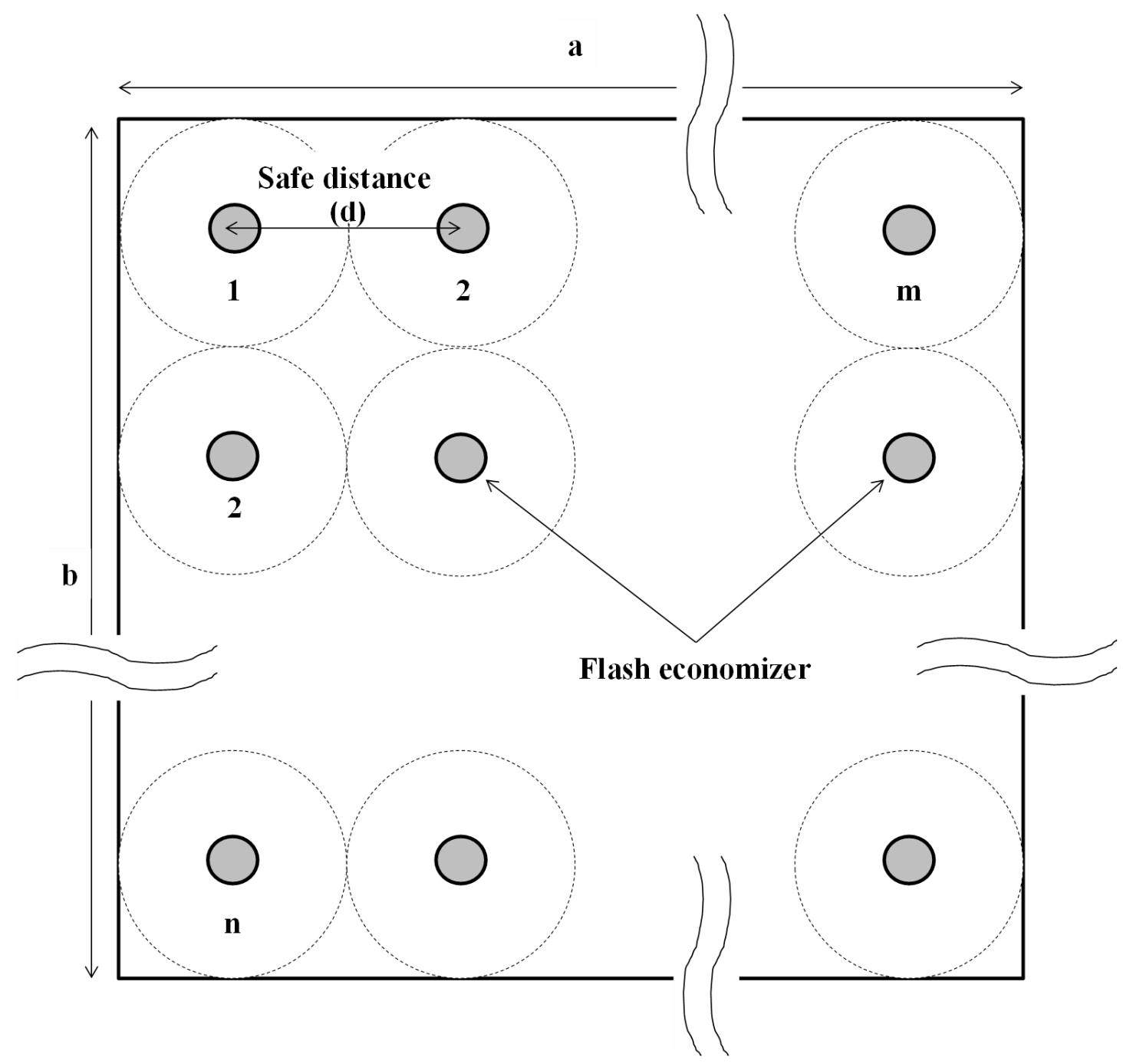

Figure 6 - Flash drum layout

561 The layout optimization involves two additional decision- variables, "a and " $b$ ". The area of the

562 layout is calculated by multiplying a and b, (Equation (17)). This area needs to be larger than the

563 summation of flash drum safe areas (Equation (18)). The required cost of piping was assumed to

564 be proportional to the total perimeter.

Area $=a \times b$ 
Saeed Eini, Hamid Reza Shahhosseini, Majid Javidi, Mahdi Sharifzadeh, Davood Rashtchian. Inherently safe and economically optimal design using multi-objective optimization: The case of a refrigeration cycle. Process Safety and Environmental Protection, 2016, 104 (Part A), 254-267.

$a \times b \geq \pi\left(\frac{d}{2}\right)^{2} \times N P P$

Perimeter $=2 \times(a+b)$

565 In conclusion, the economic objective function (the annualized cost of the plant) can be 566 presented as follows:

Annualized cost

$$
\begin{aligned}
& =\left[\text { Purchasing costs of the } \left\{\begin{array}{c}
\text { compressors } \\
\text { condenser } \\
\text { evaporators } \\
\text { flash economizers }
\end{array}\right.\right. \\
& + \text { Instrumentation cost }+ \text { Piping cost }+ \text { Land cost }] \times C R F \\
& +[\text { Compressors and condenser energy costs] }
\end{aligned}
$$

\subsection{Implementation of the optimization-simulation program}

In this paper, the superstructure is developed in the HYSYS process simulator. The formulations

570 of both risk level and plant annualized cost are codified in MATLAB as well as the MOO

571 algorithm. The optimization algorithm proposes the values of the decision variable and sends

572 them to the simulator. By fixing the specifications of the superstructure (i.e., degrees of

573 freedom), it is possible to execute the simulation program. The value of the objective functions

574 in terms of the performance of each candidate solution is evaluated using the extracted data (such

575 as flow, density, etc.) from the simulator. The iterative calculation of objectives functions

576 provides the opportunity to the optimizer to generate all non-dominated solutions (Pareto front)

577 based on the elitist non-dominated sorting genetic algorithm (NSGA-II). In the last step, final 
Saeed Eini, Hamid Reza Shahhosseini, Majid Javidi, Mahdi Sharifzadeh, Davood Rashtchian. Inherently safe and economically optimal design using multi-objective optimization: The case of a refrigeration cycle. Process Safety and Environmental Protection, 2016, 104 (Part A), 254-267.

579 this part, in order to explore the reasonable status of various solutions, the deviation index of 580 each solution from the ideal and non-ideal solution is evaluated.

\section{Results and discussion}

583 The proposed multi-objective optimization problem including economic and safety measures was

584 optimized using the NSGA-II procedure. In this regard, flash drum operating pressure ("P"), the 585 number of parallel paths ("NPPs"), the length of the plant layout ("a"), and the width of the plant 586 ("b") with corresponding constraints expressed in Equations (21) were considered as the decision 587 variables. In order to define the optimum design variables, the multi-objective optimization 588 problem can be formulated as follows:

Minimize Risk Level $f_{1}(\vec{x})$

Minimize Plant annualized costs $f_{2}(\vec{x})$

$x=\{P, N P P, a, b\}$

Subject to

$300 \leq P \leq 1200$

$1 \leq N P P S \leq 20$

$10 \leq a \leq 2000$

$10 \leq b \leq 2000$

589 In the present case study, the plant annualized cost (TAC) and risk level must be minimized

590 simultaneously (Figure 2- case a). The tuning parameters selected for the NSGA-II algorithm 591 procedure are presented in Table 4. In addition, it is possible to visualize Pareto front in a two592 dimensional space. Visualization of the Pareto front enables decision-makers to compare 593 different solutions according to their fitness with respect to the competing objectives. 
Saeed Eini, Hamid Reza Shahhosseini, Majid Javidi, Mahdi Sharifzadeh, Davood Rashtchian. Inherently safe and economically optimal design using multi-objective optimization: The case of a refrigeration cycle. Process Safety and Environmental Protection, 2016, 104 (Part A), 254-267.

Table 4 - Specified NSGA-II options for multi-objective optimization

\begin{tabular}{cc}
\hline Specified Options & value \\
\hline Population Size & 30 \\
Maximum Generations & 300 \\
Tournament Size & 2 \\
Crossover Function & Intermediate \\
Crossover Probability & 0.9 \\
Mutation Function & Constraint Dependent \\
Mutation Probability & 0.1 \\
Pareto Fraction & 0.6 \\
\hline
\end{tabular}

597 Figures (8a) show the Pareto front for multi-objective optimization of designing an inherently 598 safer refrigeration cycle, in which the competitions and conflicts between the considered 599 objectives are clearly demonstrated. Since, the range of varying of the objective functions in a 600 multi-objective optimization problem might be different, in order to facilitate the optimization 601 procedure, the dimension and scales of the objective functions were normalized. To do so, the 602 method of Euclidian was applied (Farsi and Shahhosseini, 2015). In this method, the matrix of 603 objectives at various points of the Pareto front is denoted by $F_{i j}$ where $\mathrm{i}$ is the index for each 604 point on the Pareto front and $\mathrm{j}$ is the index for each objective in the objectives space. Therefore a 605 non-dimensionalized objective $\mathrm{F}_{\mathrm{ij}}^{\mathrm{n}}$ is defined as:

$$
F_{i j}^{n}=\frac{F_{i j}}{\sqrt{\sum_{i=1}^{n} F_{i j}^{2}}}
$$

606 Therefore, all non-dominated optimal solutions are plotted in non-dimensional form in Figure 8. 
Saeed Eini, Hamid Reza Shahhosseini, Majid Javidi, Mahdi Sharifzadeh, Davood Rashtchian. Inherently safe and economically optimal design using multi-objective optimization: The case of a refrigeration cycle. Process Safety and Environmental Protection, 2016, 104 (Part A), 254-267.

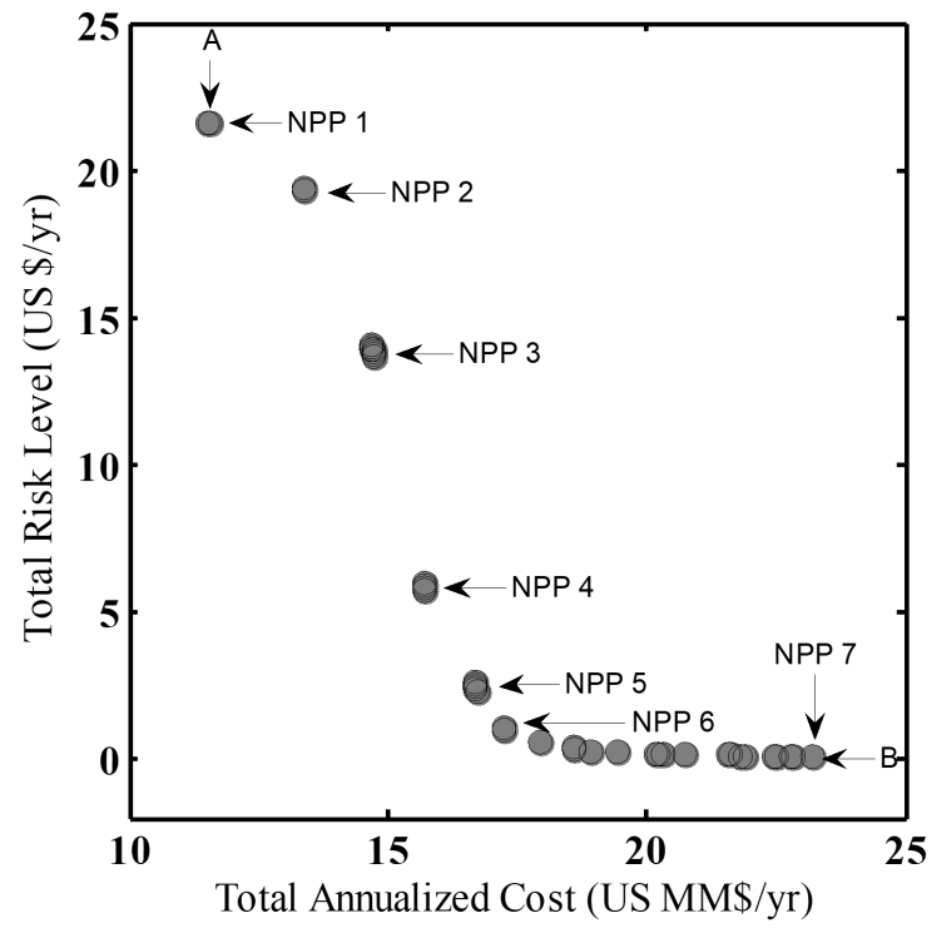

Figure 7 - Pareto optimal Front in the objectives space

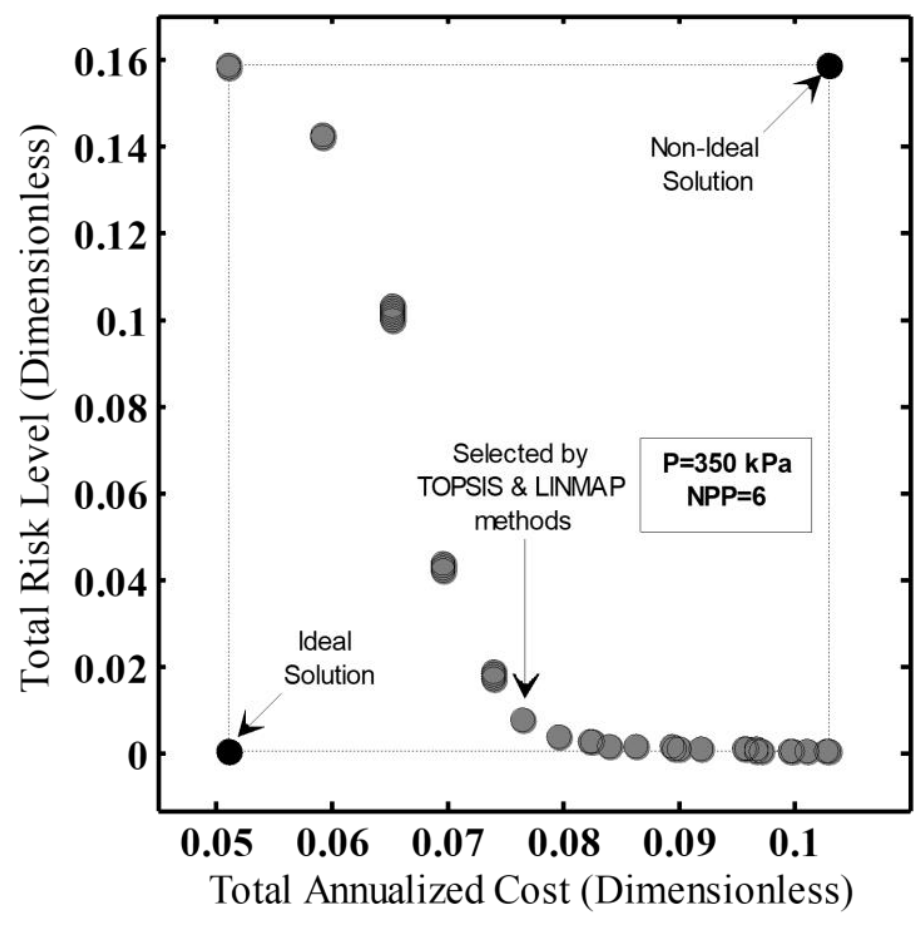

610 Figure 8 - The set of non-dimensional Pareto optimum solutions using LINMAP and TOPSIS methods to specify the final optimal design point 
Saeed Eini, Hamid Reza Shahhosseini, Majid Javidi, Mahdi Sharifzadeh, Davood Rashtchian. Inherently safe and economically optimal design using multi-objective optimization: The case of a refrigeration cycle. Process Safety and Environmental Protection, 2016, 104 (Part A), 254-267.

612 The Pareto front in Figure 7 shows that the lowest risk level is at design point B (0.0727 US

613 \$/yr), while the TAC has its highest value at this point $\left(23.2 \times 10^{6}\right.$ US \$/yr). On the other

614 extreme, the lowest TAC is at design point A $\left(11.5 \times 10^{6} \mathrm{US} \$ / \mathrm{yr}\right)$ while the risk level has its

615 highest value at this point (21.621 US \$/yr).

616 The values of decision variables are shown in Figure 7 for some of the points on the Pareto front

617 in order to clarify the trend of the Pareto front with respect to the decision variables.

618 If only the TAC was considered as the objective function (single-objective optimization), the

619 design point A (Figure 7), would be chosen as the optimal solution point of the system, while the

620 design point B (Figure 7), indicates the optimum system performance considering the risk level

621 as the objective function. In Figure 8, the ideal point is the point at which each single objective

622 has its optimum value regardless of satisfaction of other objectives (Points A and B, as discussed

623 earlier). In contrast, the non-ideal point is the point at which each objective has its worst value.

624 In Figure 8, the final optimal solution selected by LINMAP and TOPSIS decision-makings is

625 indicated. The results are an ideal solution and also a non-ideal solution.

626 Table 5 lists the final optimal results of multi-objective optimization and single-objective 627 optimization in detail. In order to quantify the fitness of various solutions, the deviation index of 628 each solution from the ideal solution is also calculated and reported. The fifth column of Table 5 629 represents the deviation indexes for the results in each optimization approach. As is clear, the 630 deviation indexes (0.0055 and 0.0055$)$ for the multi-objective optimization are less than those 631 for minimum Cost and maximum Risk which are 0.9820 and 0.018 , respectively. Therefore, the 632 final optimal solution selected by both of TOPSIS and LINMAP decision-making methods 633 which show the minimum deviation index from ideal solution in multi-objective optimization is 
Saeed Eini, Hamid Reza Shahhosseini, Majid Javidi, Mahdi Sharifzadeh, Davood Rashtchian. Inherently safe and economically optimal design using multi-objective optimization: The case of a refrigeration cycle. Process Safety and Environmental Protection, 2016, 104 (Part A), 254-267.

634 most preferred. The last row of Table 5 represents the numerical values of optimum design 635 parameters and objective functions which were corresponded to the coordinate that was 636 determined by decision-making methods.

Table 5 - Comparison between optimal solutions for multi-objective and single-objective optimizations

\begin{tabular}{|c|c|c|c|c|c|c|}
\hline \multirow[t]{2}{*}{ Optimization algorithms } & \multirow{2}{*}{$\begin{array}{l}\text { Decision- } \\
\text { makings }\end{array}$} & \multicolumn{2}{|c|}{ Objectives } & \multirow{2}{*}{$\begin{array}{l}\text { Deviation index } \\
\mathrm{d}\end{array}$} & \multirow[t]{2}{*}{$\mathrm{P}(\mathrm{kpa})$} & \multirow[t]{2}{*}{ NPP } \\
\hline & & $\begin{array}{l}\text { Non-dimensional } \\
\text { TAC }\end{array}$ & $\begin{array}{l}\text { Non-dimensional } \\
\text { Risk }\end{array}$ & & & \\
\hline \multirow[t]{2}{*}{ NSGA-II } & LINMAP & 0.0766 & 0.0075 & 0.0055 & 350 & 1 \\
\hline & TOPSIS & 0.0766 & 0.0075 & 0.0055 & 350 & 1 \\
\hline Minimum TAC & & 0.0511 & 0.1585 & 0.9820 & 383 & 1 \\
\hline Minimum Risk Level & & 0.1029 & 0.0053 & 0.018 & 351 & 20 \\
\hline \multicolumn{7}{|c|}{ Optimum design variables and objective functions based on TOPSIS and LINMAP decision-making } \\
\hline $\mathrm{P}(\mathrm{kpa})$ & NPP & TAC (US & $\$ / \mathrm{yr})$ & Risk (US \$/. & & \\
\hline 350 & 6 & $17.3 \times 1$ & & 1.0262 & & \\
\hline
\end{tabular}

639 The value of optimization variables for the base case design (Figure 4), $\mathrm{P}=676 \mathrm{kPa}, \mathrm{NPP}=1$ ), the 640 solution reported by Eini et al. (2015) $(\mathrm{P}=600 \mathrm{kPa}, \mathrm{NPP}=11)$, and the optimum solution found in

641 this study $(\mathrm{P}=350 \mathrm{kPa}, \mathrm{NPP}=6)$ are shown in Table 6. Table 6 suggests that, in comparison to 642 the base-case, for 19 percent increase in the TAC, it is possible to increase the level of process 643 safety by 1 order of magnitude. With respect to the previous results by Eini et al. (2015), the new 644 solution is much more realistic as the number of parallel paths is almost halved (i.e., less 645 complexity) but the associated risk is only increased by $17 \%$, In addition, the new solution 646 considers the costs of land-use, piping, and instrumentation that were ignored in the previous 647 study. 
Saeed Eini, Hamid Reza Shahhosseini, Majid Javidi, Mahdi Sharifzadeh, Davood Rashtchian. Inherently safe and economically optimal design using multi-objective optimization: The case of a refrigeration cycle. Process Safety and Environmental Protection, 2016, 104 (Part A), 254-267.

(Eini et al., 2015), and multi-objective optimization case (present work)

\begin{tabular}{cccc}
\hline Optimum point characterizations & Base-case & Eini et al. (2015) & Present study \\
\hline Drum operating pressure (kPa) & 676 & 600 & 350 \\
Number of parallel paths (NPP) & 1 & 11 & 6 \\
Plant annualized costs (US \$/yr) & $14.5 \times 10^{6}$ & $22.1 \times 10^{6}$ & $17.3 \times 10^{6}$ \\
Risk (US \$/yr) & 21.8256 & 0.4462 & 1.0262 \\
\hline
\end{tabular}

652 In this paper, a general framework to design inherently safer processes is developed. In the 653 proposed framework, the two competing and conflicting objectives of process economy and 654 inherent safety are considered simultaneously. The new algorithm is developed in order to 655 consider the level of process inherent safety based on the frequency and the consequence of 656 potential accidents. The solution of the multi-objective optimization (MOO) forms a Pareto front 657 which quantifies the trade-off between competing objectives and enables the decision-makers to 658 choose the optimal design based on the satisfaction of the objectives.

659 The proposed optimization framework was implemented for the case of a simple refrigeration 660 cycle. The objective functions used in the case study were the plant risk level as well as the plant 661 total annualized costs. Furthermore, a layout optimization was implemented in order to consider, 662 the costs of instrumentation, piping, and land-use. NSGA II was utilized as the MOO algorithm 663 in order to produce the Pareto front. Two well-known and common types of decision-making 664 techniques (LINMAP and TOPSIS) were applied in order to specify the final optimal solution. 665 The results of multi-objective optimization problem suggested that for about 19 percent increase 666 in the total annualized costs, it is possible to decrease the risk level by one order of magnitude in 
Saeed Eini, Hamid Reza Shahhosseini, Majid Javidi, Mahdi Sharifzadeh, Davood Rashtchian. Inherently safe and economically optimal design using multi-objective optimization: The case of a refrigeration cycle. Process Safety and Environmental Protection, 2016, 104 (Part A), 254-267.

667 comparison with the base-case. While the demonstrating example of the refrigeration cycle 668 provides the proof of concept, the results are deemed to be general and extendable to other 669 industrial processes.

670 The dynamic behavior of a process strongly depends on its design. Therefore, the decision671 making domains of process and control engineers overlap (Sharifzadeh and Thornhill, 2012, 672 2013; Sharifzadeh, 2013a, 2013b). Moreover, it should be noted that accidents have a dynamic

673 nature. Therefore, the inherent safety level of a process should be assessed not only in the steady

674 state condition but also in dynamic mode and the future researches should address the dynamic 675 aspects of ISD strategies. Furthermore, there is a strong interaction between involved materials 676 and process inherent safety (Ten et al., 2015). Therefore, there are great opportunities for 677 integrating ISD concepts during product design stage using computer-aided molecular design 678 (CAMD) techniques. Based on CAMD techniques, it is possible to select or design new materials 679 that meet specific thermophysical properties. Consequently, CAMD can be used as a good tool in 680 order to design new molecules that feature desirable safety indicators such as moderated 681 flammability, toxicity, and etc. This leads to implementation of the substitution strategy of 682 inherent safety.

$\begin{array}{ll}\mathrm{F}^{\text {non-ideal }} & \text { non-ideal solution vector on Pareto front } \\ \mathrm{C}_{\text {total }} & \text { total cost of the accident [accident cost, for example, \$] } \\ \mathrm{F}^{\text {ideal }} & \text { ideal solution vector on Pareto front } \\ \mathrm{P}_{\mathrm{ch}} & \text { chiller (evaporator)pressure }[\mathrm{kPa}] \\ \mathrm{P}_{\text {cond }} & \text { condenser pressure }[\mathrm{kPa}]\end{array}$


Saeed Eini, Hamid Reza Shahhosseini, Majid Javidi, Mahdi Sharifzadeh, Davood Rashtchian. Inherently safe and economically optimal design using multi-objective optimization: The case of a refrigeration cycle. Process Safety and Environmental Protection, 2016, 104 (Part A), 254-267.

\begin{tabular}{|c|c|}
\hline $\mathrm{P}_{\mathrm{nf}}$ & probability of occurrence of an accident as an independent event \\
\hline$C_{(x . y)_{i}}$ & consequence of scenario $i$ in the risk receptor location $(x, y)$ [accident cost] \\
\hline$F_{i j}$ & solution i of jth objective on the Pareto front \\
\hline$P_{\text {econ }}$ & optimum drum operating pressure $[\mathrm{kPa}]$ \\
\hline \multirow[t]{2}{*}{$R_{(x, y)_{i}}$} & risk level associated with an accident scenario $i$ in the risk receptor location $(x, y)$ \\
\hline & {$\left[\right.$ accident cost $*$ time $\left.^{-1}\right]$} \\
\hline$R_{(x, y)}$ & risk level associated with all scenarios in the $(x, y)$ location [accident cost* time ${ }^{-1}$ ] \\
\hline$R_{n f}$ & risk associated with the simultaneous explosion of " $\mathrm{n}_{\mathrm{f}}$ " drums [accident cost* time \\
\hline & $\left.{ }^{1}\right]$ \\
\hline$R_{\text {overall }}$ & overall risk [accident cost* time $^{-1}$ ] \\
\hline$Y_{i}$ & assessment parameter in decision-making \\
\hline \multirow[t]{2}{*}{$c_{n}^{n_{f}}$} & number of accident combinations that can occur when $\mathrm{n}_{\mathrm{f}}$ units suffer an occurrence \\
\hline & out of " $n$ " \\
\hline$d_{i-}$ & distance of each solution (i) from the non-ideal solution \\
\hline$d_{i+}$ & distance of every solution (i) on the Pareto front from the ideal solution \\
\hline$f_{B L E V E / F I R E B A L L}$ & frequency of a BLEVE/fireball outcome $\left[\right.$ time $\left.^{-1}\right]$ \\
\hline$f_{i}$ & frequency of scenario $i\left[\right.$ time $\left.^{-1}\right]$ \\
\hline$f_{k}(\vec{x})$ & objective function number $\mathrm{k}$ ( $\mathrm{x}$ is a vector of decision variables) \\
\hline$n_{f}$ & number of drums that suffer an occurrence \\
\hline ALARP & As Low As Reasonably Practicable \\
\hline BLEVE & Boiling Liquid Expanding Vapor Explosion \\
\hline CAMD & Computer-Aided Molecular Design \\
\hline $\mathrm{CRF}$ & Capital Recovery Factor \\
\hline ETA & Event Tree Analysis \\
\hline FTA & Fault Tree Analysis \\
\hline ISD & Inherently Safer Design \\
\hline ISEOD & Inherently Safer and Economically Optimal Design \\
\hline LINMAP & Linear Programming Technique for Multidimensional Analysis of Preference \\
\hline MOO & Multi-Objective Optimization \\
\hline$n$ & the total number of drums in the cycle \\
\hline
\end{tabular}


Saeed Eini, Hamid Reza Shahhosseini, Majid Javidi, Mahdi Sharifzadeh, Davood Rashtchian. Inherently safe and economically optimal design using multi-objective optimization: The case of a refrigeration cycle. Process Safety and Environmental Protection, 2016, 104 (Part A), 254-267.

NPP Number Of Parallel Paths

NSGA Non-Dominated Sorting Genetic Algorithm

QRA Quantitative Risk Assessment

TAC Total Annualized Cost

TOPSIS Technique for Order Preference by Similarity to an Ideal Solution

VCE Vapor Cloud Explosion

VCF Vapor Cloud Fire

687 Ahmad, S.I., Hashim, H., Hassim, M.H., 2014. Numerical Descriptive Inherent Safety Technique 688 (NuDIST) for inherent safety assessment in petrochemical industry. Process Saf. Environ. Prot. $68992,379-389$.

690 Ahmad, S.I., Hashim, H., Hassim, M.H., Abdul, Z., 2015. Inherent Safety Assessment Technique 691 for Separation Equipment in Preliminary Engineering Stage. Chem. Eng. Trans. 45, 1123-1128.

692 Ahmad, S.I., Hashim, H., Hassim, M.H., Muis, Z.A., 2016. Inherent Safety Assessment of 693 Biodiesel Production: Flammability Parameter. Procedia Eng. 148, 1177-1183.

694 API, 2008. Recommended Practice 581: Risk based inspection, Second ed. American Petroleum 695 Institute, Washington.

696 API, 1995. Recommended Practice 752: Management of hazards associated with location of 697 process plant buildings, second ed. American Petroleum Institute, Washington.

698 Bernechea, E.J., Arnaldos Viger, J., 2013. Design optimization of hazardous substance storage 699 facilities to minimize project risk. Saf. Sci. 51, 49-62.

700 Reference Manual BEVI Risk Assessments version 3.2, 2009. National Institute of Public Health 701 and the Environment (RIVM), Centre for External Safety, Bilthoven.

702 Casal, J., 2008. Evaluation of the Effects and Consequences of Major Accidents in Industrial 703 Plants. Elsevier, Amsterdam.

704 CCPS, 2000. Guidelines for Chemical Process Quantitative Risk Analysis, second ed. American 705 Institute of Chemical Engineers, New York.

706 CCPS, 2003. Guidelines for Facility Siting and Layout. American Institute of Chemical 707 Engineers, New York. 
Saeed Eini, Hamid Reza Shahhosseini, Majid Javidi, Mahdi Sharifzadeh, Davood Rashtchian. Inherently safe and economically optimal design using multi-objective optimization: The case of a refrigeration cycle. Process Safety and Environmental Protection, 2016, 104 (Part A), 254-267.

CCPS, 2009. Inherently safer chemical processes: a life cycle approach, second ed. John Wiley \& Sons, New Jersey.

Chan, I., Alwi, S.R.W., Hassim, M.H., Manan, Z.A., Klemeš, J.J., 2014. Heat Exchanger Network Design Considering Inherent Safety. Energy Procedia 61, 2469-2473.

Deb, K., 2005. Multi-Objective Optimization, in: Burke, E., Kendall, G. (Eds.), Search Methodologies. Springer, New York, pp. 273-316.

Edwards, D.W., Lawrence, D., 1993. Assessing the inherent safety of chemical process routes: Is there a relation between plant costs and inherent safety. Process Saf. Environ. Prot. 71, 252-258.

Ee, A.W.L., Shaik, S.M., Khoo, H.H., 2015. Development and application of a Combined Approach for Inherent Safety and Environmental (CAISEN) assessment. Process Saf. Environ. Prot. 96, 138-148.

Eini, S., Abdolhamidzadeh, B., Reniers, G., Rashtchian, D., 2015. Optimization procedure to select an inherently safer design scheme. Process Saf. Environ. Prot. 93, 89-98.

Farsi, M., Shahhosseini, H., 2015. A modified membrane SMR reactor to produce large-scale syngas: modeling and multi objective optimization. Chem. Eng. Process. Process Intensif. 97, 169-179.

Gebreslassie, B.H., Guillén-Gosálbez, G., Jiménez, L., Boer, D., 2009. Design of environmentally conscious absorption cooling systems via multi-objective optimization and life cycle assessment. Appl. Energy 86, 1712-1722.

Groos-Gerardin, K., Perrin, L., Falk, V., Dufaud, O., 2015. Combining product engineering and inherent safety to improve the powder impregnation process. J. Loss Prev. Process Ind. 38, 1-10.

Hafizan, A.M., Alwi, S.R.W., Manan, Z.A., Klemeš, J.J., 2016. Optimal heat exchanger network synthesis with operability and safety considerations. Clean Technol. Environ. Policy 1-20.

Han, K., Cho, S., Yoon, E.S., 2013. Optimal layout of a chemical process plant to minimize the risk to humans. Procedia Comput. Sci. 22, 1146-1155.

Heikkilä, A.-M., 1999. Inherent Safety in Process Plant Design: An Index-Based Approach. VTT publications, Finland.

Hendershot, D.C., 2000. Process minimization: making plants safer. Chem. Eng. Prog. 96, 35-40.

Javidi, M., Abdolhamidzadeh, B., Reniers, G., Rashtchian, D., 2015. A multivariable model for estimation of vapor cloud explosion occurrence possibility based on a Fuzzy logic approach for flammable materials. J. Loss Prev. Process Ind. 33, 140-150. 
Saeed Eini, Hamid Reza Shahhosseini, Majid Javidi, Mahdi Sharifzadeh, Davood Rashtchian. Inherently safe and economically optimal design using multi-objective optimization: The case of a refrigeration cycle. Process Safety and Environmental Protection, 2016, 104 (Part A), 254-267.

Jha, V., Pasha, M., Zaini, D., 2016. Enhanced Inherent Safety Intervention Framework. Procedia Eng. 148, 1051-1057.

Khan, F., Rathnayaka, S., Ahmed, S., 2015. Methods and models in process safety and risk management: Past, present and future. Process Saf. Environ. Prot. 98, 116-147.

Khan, F.I., Amyotte, P.R., 2002. Inherent safety in offshore oil and gas activities: a review of the present status and future directions. J. Loss Prev. Process Ind. 15, 279-289.

Khan, F.I., Amyotte, P.R., 2003. How to make inherent safety practice a reality. Can. J. Chem. Eng. 81, 2-16.

Kletz, T.A., 1991. Plant Design for Safety: A User-Friendly Approach. Hemisphere Publishing Corporation, New York.

Kletz, T.A., Amyotte, P., 2010. Process Plants: A Handbook for Inherently Safer Design, second ed. CRC Press, Florida.

Knowles, J., Corne, D., 1999. The Pareto archived evolution strategy: A new baseline algorithm for multi-objective optimization", In Proceeding of the 1999 Congress on Evolutionary Computation. IEEE Service Center.

Konak, A., Coit, D.W., Smith, A.E., 2006. Multi-objective optimization using genetic algorithms: A tutorial. Reliab. Eng. Syst. Saf. 91, 992-1007.

Li, Y., Liao, S., Liu, G., 2015. Thermo-economic multi-objective optimization for a solar-dish Brayton system using NSGA-II and decision making. Int. J. Electr. Power Energy Syst. 64, 167175.

Liew, W.H., Hassim, M.H., Ng, D.K.S., 2014. Sustainability assessment for biodiesel production via fuzzy optimisation during research and development (R\&D) stage. Clean Technol. Environ. Policy 16, 1431-1444.

Liew, W.H., Hassim, M.H., Ng, D.K.S., Chemmangattuvalappil, N., 2015. Systematic Framework for Sustainability Assessment of Biodiesel Production: Preliminary Engineering Stage. Ind. Eng. Chem. Res. 54, 12615-12629.

Liew, W.H., Hassim, M.H., Ng, D.K.S., 2016. Sustainability assessment framework for chemical production pathway: Uncertainty analysis. J. Environ. Chem. Eng.

Ling, S., Hassim, M.H., Ng, D.K.S., Seng, W., 2015. Review on Sustainability Assessment of Integrated Biorefineries based on Environmental , Health and Safety Perspectives 45, 13991404. 
Saeed Eini, Hamid Reza Shahhosseini, Majid Javidi, Mahdi Sharifzadeh, Davood Rashtchian. Inherently safe and economically optimal design using multi-objective optimization: The case of a refrigeration cycle. Process Safety and Environmental Protection, 2016, 104 (Part A), 254-267.

770

771

772

773

774

775

776

777

778

779

780

781

782

783

784

785

786

787

788

789

790

791

792

793

794

795

796

797

798

799

LNE, 2009. Handbook of failure frequencies.

Madetoja, E., Ruotsalainen, H., Monkkonen, V.M., Hamalainen, J., Deb, K., 2008. Visualizing multi-dimensional Pareto-optimal fronts with a 3D virtual reality system, Computer Science and Information Technology, 2008. IMCSIT 2008. International Multi conference on, pp. 907-913.

Mannan, S., 2013. Lees' Process Safety Essentials: Hazard Identification, Assessment and Control. Butterworth-Heinemann, Oxford.

Manning, F.S., Thompson, R.E., 1991. Oilfield processing of petroleum: Natural gas. Pennwell books, Oklahoma.

Medina-Herrera, N., Jiménez-Gutiérrez, A., Mannan, M.S., 2014. Development of inherently safer distillation systems. J. Loss Prev. Process Ind. 29, 225-239.

Medina, H., Arnaldos, J., Casal, J., 2009. Process design optimization and risk analysis. J. Loss Prev. Process Ind. 22, 566-573.

Ng, R., Hassim, M., Ng, D., 2013. Process synthesis and optimization of a sustainable integrated biorefinery via fuzzy optimization. AIChE.

Ng, R.T.L., Hassim, M.H., Hurme, M., 2014a. A heuristic framework for inherent occupational health assessment in chemical process design. Chem. Eng. Trans. 39, 955-960.

Ng, R.T.L., Hassim, M.H., Ng, D.K.S., Tan, R.R., El-Halwagi, M.M., 2014b. Multi-objective Design of Industrial Symbiosis in Palm Oil Industry, Proceedings of the 8th International Conference on Foundations of Computer-Aided Process Design. Elsevier.

Ng, R.T.L., Hassim, M.H., 2015. Strategies for assessing and reducing inherent occupational health hazard and risk based on process information. Process Saf. Environ. Prot. 97, 91-101.

Ng, R.T.L., Tan, R.R., Hassim, M.H., 2015. P-Graph Methodology for Bi-objective Optimisation of Bioenergy Supply Chains : Economic and Safety Perspectives 45, 1357-1362.

OGP, 2010. Report no. 434-1: Risk assessment data directory: Process release frequencies. International Association of Oil and Gas Procedures, Brussels.

Pandian, S., Hassim, M.H., Ng, R.T.L., Hurme, M., 2015. Designing an inherently healthier process based on inherently safer design (ISD) concept: Research and development stage. Clean Technol. Environ. Policy 17, 1247-1259.

Patel, S.J., Ng, D., Mannan, M.S., 2010. Inherently safer design of solvent processes at the conceptual stage: Practical application for substitution. J. Loss Prev. Process Ind. 23, 483-491. 
Saeed Eini, Hamid Reza Shahhosseini, Majid Javidi, Mahdi Sharifzadeh, Davood Rashtchian. Inherently safe and economically optimal design using multi-objective optimization: The case of a refrigeration cycle. Process Safety and Environmental Protection, 2016, 104 (Part A), 254-267.

800 Perry, J.H., 1950. Chemical engineers' handbook. J. Chem. Educ. 27, 533.

801 Ramadhan, N.J., Wan, Y.K., Ng, R.T.L., Ng, D.K.S., Hassim, M.H., Aviso, K.B., Tan, R.R., 802 2014. Life cycle optimisation (LCO) of product systems with consideration of occupational 803 fatalities. Process Saf. Environ. Prot. 92, 390-405.

804 Scarponi, G.E., Guglielmi, D., Casson Moreno, V., Cozzani, V., 2016. Assessment of inherently 805 safer alternatives in biogas production and upgrading. AIChE J. 62, 2713-2727.

806 Seider, W.D., Seader, J.D., Lewin, D.R., 2009. Product \& Process Design Principles: Synthesis, 807 Analysis and Evaluation. John Wiley \& Sons, New York.

808 Shariff, A. M., Rusli, R., Leong, C.T., Radhakrishnan, V.R., Buang, A., 2006. Inherent safety 809 tool for explosion consequences study. J. Loss Prev. Process Ind. 19, 409-418.

810 Shariff, A.M., Zaini, D., 2010. Toxic release consequence analysis tool (TORCAT) for 811 inherently safer design plant. J. Hazard. Mater. 182, 394-402.

812 Shariff, A.M., Wahab, N.A., Rusli, R., 2016. Assessing the hazards from a BLEVE and 813 minimizing its impacts using the inherent safety concept. J. Loss Prev. Process Ind. 41, 303-314. 814 doi:10.1016/j.jlp.2016.01.001

815 Sharifzadeh, M., Rashtchian, D., Pishvaie, M.R., Thornhill, N.F., 2011. Energy induced 816 separation network synthesis of an olefin compression section: A case study. Ind. Eng. Chem. 817 Res. 50, 1610-1623.

818 Sharifzadeh, M., Thornhill, N.F., 2012. Optimal selection of control structure using a steady819 state inversely controlled process model. Comput. Chem. Eng. 38, 126-138.

820 Sharifzadeh, M., Thornhill, N.F., 2013. Integrated design and control using a dynamic inversely 821 controlled process model. Comput. Chem. Eng. 48, 121-134.

822 Sharifzadeh, M., 2013a. Integration of process design and control: A review, Chemical 823 Engineering Research and Design. Institution of Chemical Engineers.

824 Sharifzadeh, M., 2013b. Implementation of a steady-state inversely controlled process model for 825 integrated design and control of an ETBE reactive distillation. Chem. Eng. Sci. 92, 21-39.

826 Smith, R., 2005. Chemical Process Design and Integration. John Wiley \& Sons Ltd, Chichester.

827 Ten, J.Y., Hassim, M.H., Chemmangattuvalappil, N., Ng, D.K.S., 2015. A Novel Chemical 828 Product Design Framework with the Integration of Safety and Health Aspects. J. Loss Prev. 829 Process Ind. 40, 67-80. 
Saeed Eini, Hamid Reza Shahhosseini, Majid Javidi, Mahdi Sharifzadeh, Davood Rashtchian. Inherently safe and economically optimal design using multi-objective optimization: The case of a refrigeration cycle. Process Safety and Environmental Protection, 2016, 104 (Part A), 254-267.

830 TOTAL, 2012. GS EP SAF 253: General Specification for Safety. TOTAL Publication, Paris.

831 Towler, G.P., Sinnott, R.K., 2008. Chemical Engineering Design: Principles, Practice, and 832 Economics of Plant and Process Design. Elsevier, Amsterdam.

833 Yu, P.-L., 2013. Multiple-Criteria Decision Making: Concepts, Techniques, and Extensions. 834 Springer Science \& Business Media, New York.

835 Yue, Z., 2011. A method for group decision-making based on determining weights of decision 836 makers using TOPSIS. Appl. Math. Modell. 35, 1926-1936. 